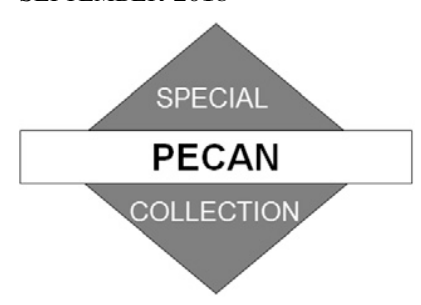

\title{
Trapped Gravity Waves and Their Association with Turbulence in a Large Thunderstorm Anvil during PECAN
}

\author{
STANLEy B. TRIER AND Robert D. SHARMAN \\ National Center for Atmospheric Research, Boulder, Colorado
}

(Manuscript received 29 April 2018, in final form 5 July 2018)

\begin{abstract}
Geostationary Operational Environmental Satellite-14 (GOES-14) 1-km visible satellite data with 1-min frequency revealed horizontally propagating internal gravity waves emanating from tropopause-penetrating deep convection on 3-4 June 2015 during the Plains Elevated Convection at Night (PECAN) field experiment. These waves had horizontal wavelengths of $\sim 6-8 \mathrm{~km}$ and approximate ground-relative phase speeds of $35 \mathrm{~m} \mathrm{~s}^{-1}$. PECAN radiosonde data are used to document the environment supporting the horizontally propagating gravity waves within the 200-km-long downstream thunderstorm anvil. Comparisons among soundings within the anvil core, at the downstream anvil edge, and outside of the anvil, together with supporting high-resolution numerical simulations, establish the importance of the storm-induced uppertropospheric/lower-stratospheric (UTLS) outflow in providing conditions allowing vertical trapping of internal gravity waves over large horizontal distances within the mesoscale anvil. Turbulence was reported by commercial aviation in proximity to the gravity waves near the downstream anvil edge. The simulations suggest that the strongest turbulence was consistent with a mesoscale destabilization of the outer portion of the downstream anvil at elevations immediately below the outflow jet, where differential temperature advection owing to the strong associated vertical shear reduces static stability. The simulated gravity waves are trapped at this elevation and extend for several kilometers below. Local minima of moist gradient Richardson number occur immediately above the simulated warm gravity wave temperature perturbations at anvil base, suggesting a possible role these waves could play in establishing precise locations for the onset of turbulence.
\end{abstract}

\section{Introduction}

Tropopause-penetrating deep convection, which often manifests in visible satellite imagery as localized overshooting cloud domes surrounded by broader anvil regions, is associated with a variety of hazards including severe surface weather, lightning, and aviation turbulence. In particular, Bedka et al. (2010) found that these deep convective storms were associated with a $45 \%$ greater likelihood of turbulence for aircraft that flew within $5 \mathrm{~km}$ of their overshooting tops.

An important factor that can contribute to turbulence in many of these cases is the excitation of internal gravity waves that occurs when the deep convection within the overshooting tops intrudes into the statically stable lower stratosphere. The resulting gravity waves can propagate vertically and constitute a potential hazard above the cloud top or, under certain conditions, be

Corresponding author: Stanley B. Trier, trier@ucar.edu vertically trapped (ducted) and maintain their coherence as they propagate horizontally, thereby influencing the threat of turbulence at significant horizontal distances from deep convection [see Sharman and Trier (2018) for a review]. In the current study we use data from a dense radiosonde network, along with supporting highresolution numerical simulations, to characterize the environment of horizontally propagating gravity waves emanating from upstream deep convection and explore the possible role of these waves on upper-troposphere/ lower-stratosphere (UTLS) turbulence.

For vertically propagating convectively induced gravity waves, high-resolution modeling studies have indicated that turbulence can occur above both growing (e.g., Lane et al. 2003) and dissipating (e.g., Kim and Chun 2012) deep convection. The turbulence in some cases is associated with a critical level at which the horizontal phase velocity of the wave equals that of the environmental flow, which prevents further vertical propagation. Underneath the critical level, waves can 
amplify (Bretherton 1966), overturn, and subsequently break into patches of turbulence (e.g., Dörnbrack et al. 1995).

In some cases, such wave breaking above overshooting tops can result in moist tropospheric air being injected into the lower stratosphere and producing visible cirrus plumes located up to several kilometers above the convective-storm outflow (e.g., Levizzani and Setvák 1996; Wang 2003, 2007; Homeyer et al. 2017). However, in many other cases (e.g., Lane et al. 2003; Kim and Chun 2012; Trier et al. 2012) wave-breaking above deep convection is not associated with any cloudiness, and turbulence within clear air may be encountered.

Increased probabilities of turbulence at significant horizontal distances (e.g., 10-100 km) from active deep convection, which are more difficult to attribute to the breaking of vertically propagating gravity waves, have also been established in both climatologies (e.g., Lane et al. 2012) and a series of model-based case studies (e.g., Barber et al. 2018). Lane et al. (2012) used numerical simulations to demonstrate that ducted horizontally propagating gravity waves in a background environment with small gradient Richardson number Ri could result in further Ri reductions that supported shearing instabilities. This result provided a possible explanation for severe turbulence encountered by commercial aircraft at UTLS cruising altitudes adjacent to, but outside of, the cloud boundary of deep convection in northwest Indiana on 5 August 2005 (Fovell et al. 2007).

Striking visual evidence of ducted short-wavelength horizontally propagating gravity waves emanating from overshooting deep convection is found in the Geostationary Operational Environmental Satellite-14 (GOES-14) 1-km visible satellite imagery on 3-4 June 2015 (Fig. 1). During the storm life cycle there were pilot reports (PIREPs) and recorded eddy dissipation rates (EDRs; section 2) consistent with UTLS turbulence both on the upwind side of the storm (Fig. 1b) and later in the vicinity of gravity waves near the downstream anvil edge (Figs. 1c,d). Unlike in the 5 August 2005 case, only light and moderate turbulence intensities were reported on 4 June 2015. However, the 4 June 2015 case occurred during an intensive observing period (IOP) of the Plains Elevated Convection at Night (PECAN) field campaign (Geerts et al. 2017). Though this IOP was not specifically intended for observing gravity waves and UTLS turbulence, the 90-min sounding frequency from closely spaced fixed profiling (FP) sites (Fig. 1) offers a rare and valuable opportunity to document and examine conditions leading to wave trapping in a large thunderstorm anvil.

Both long-lived isolated thunderstorms and intense mesoscale convective systems (MCSs) frequently occur under conditions of deep tropospheric environmental vertical wind shear (e.g., Coniglio et al. 2006). However, Zovko-Rajak and Lane (2014) demonstrated that conditions favoring gravity wave ducting can occur in idealized simulations of thunderstorm outflows for cases in which there is no background UTLS vertical shear. This motivates one of the questions addressed in the current study, which is the following: To what extent do mesoscale flow modifications associated with upstream deep convection contribute to wave trapping in observed cases with more complicated background UTLS wind profiles?

Though turbulence is typically less severe than in active regions of deep convection, large thunderstorm anvils are locations where turbulence resulting from a variety of different possible mechanisms is often observed (e.g., Petre and Verlinde 2004; Muhlbauer et al. 2014). This motivates our use of multiscale nested highresolution simulations to gain insight into the possible role(s) trapped gravity waves may have on the UTLS turbulence in this observed case.

The remainder of the paper is organized as follows. In section 2 we overview the data sources used in this study. Section 3 discusses the initiation and life cycle of the parent thunderstorm, the modification of conditions in its associated mesoscale UTLS outflow, and how these modifications influence both ducting of internal gravity waves and the susceptibility to turbulence. In section 4 we describe the numerical model and present simulations that illustrate possible influences of the gravity waves and other mechanisms on turbulence.

\section{Data}

Both PIREPs and automated in situ turbulence detection systems are used in this study. The in situ measurements, which were available from a subset of the Boeing 737 and 757 commercial aviation fleet that were opportunistically traveling in the vicinity of the storm, provide estimates of the vertical component of the atmospheric energy or eddy dissipation rate (EDR) $\varepsilon^{1 / 3}$ $\left(\mathrm{m}^{2 / 3} \mathrm{~s}^{-1}\right)$. Advantages of EDR estimates (Sharman et al. 2014) compared to PIREPs are the 1-min regular frequency of reported maximum values, absence of subjectivity of turbulence intensity (turbulence values in PIREPs are dependent on aircrew perception), and the mitigation of temporal and spatial uncertainties associated with PIREPs (Schwartz 1996). However, there is some variability in the EDR thresholds that have been used historically to categorize different intensities of turbulence. Herein, we use recent threshold values based on comparisons to PIREPs of $\sim 0.05 \mathrm{~m}^{2 / 3} \mathrm{~s}^{-1}$ for light, $0.20 \mathrm{~m}^{2 / 3} \mathrm{~s}^{-1}$ for moderate, and $0.45 \mathrm{~m}^{2 / 3} \mathrm{~s}^{-1}$ for 

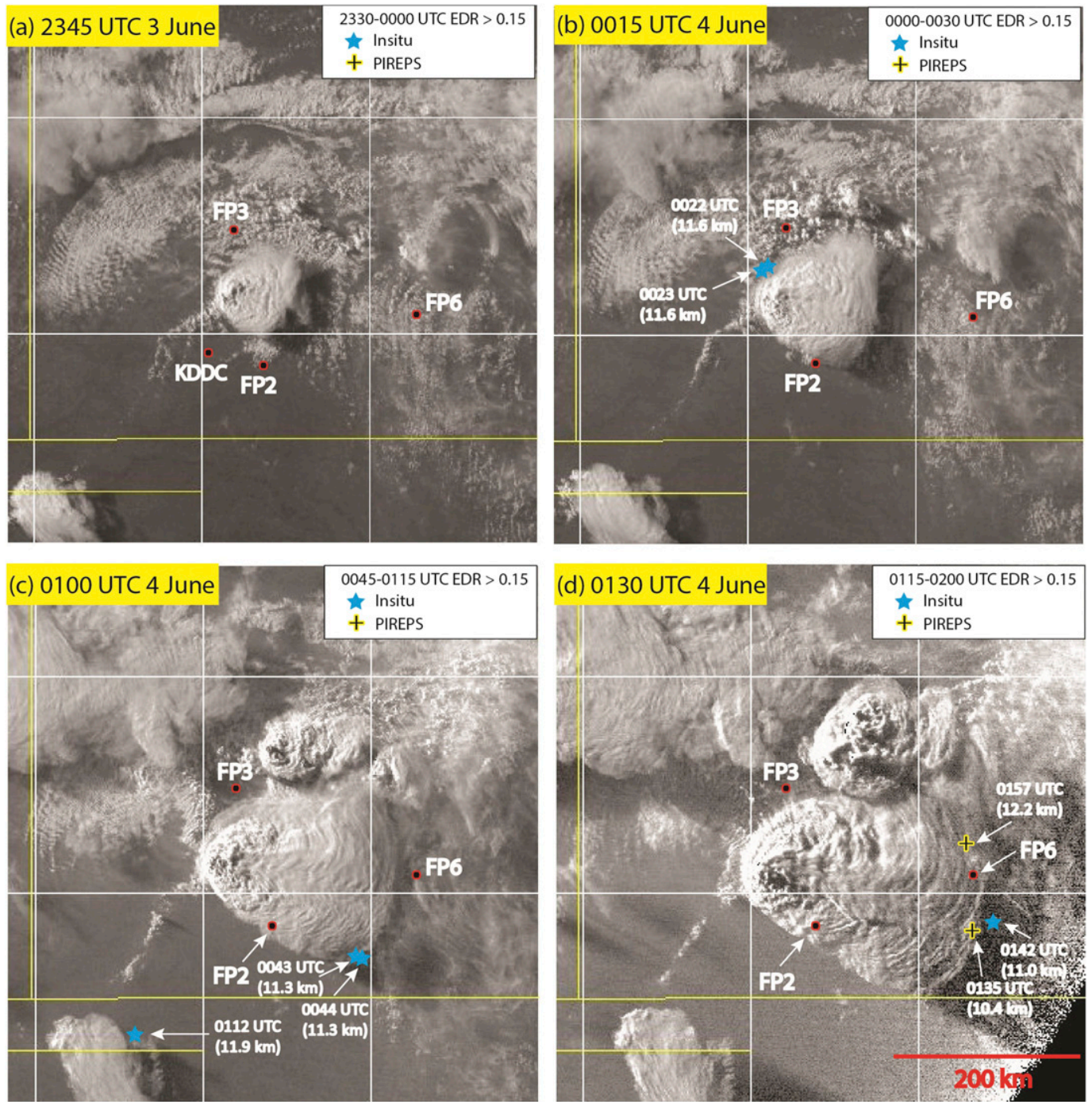

FIG. 1. Geostationary Operational Environmental Satellite-14 (GOES-14) 1-km pixel resolution imagery with overlaid locations of pilot reports (PIREPS) and automated reports of in situ eddy dissipation rate (EDR) for turbulence having light-to-moderate or greater intensities at the indicated times and heights (km MSL). Launch sites of National Weather Service (KDDC) and PECAN research radiosondes (FP2, FP3, and FP6), displayed or analyzed in Figs. 3, 4, 8, 9, and 10, are indicated by the black-filled red circles.

severe turbulence affecting medium-sized aircraft, as suggested by Lane and Sharman (2014). PIREP values are converted to corresponding EDR based on the comparisons in Sharman et al. (2014).

Measurements from multiple conventional and PECAN data platforms are used to document both the deep convective storm that was the source of the gravity waves on 4 June, the low- to midtropospheric environment that led to storm initiation and decay, and the UTLS environment in which both the waves and turbulence occurred. The deep convection across the PECAN region is examined using NEXRAD radar mosaics of maximum column reflectivity and GOES-14 visible satellite data imagery (Fig. 1) at high spatial (1-km pixel size) and temporal (1 min) resolution. The latter is also used to identify aspects of the gravity waves, including their horizontal wavelength and approximate ground-relative phase speed. Surface airways observations (SAOs) are objectively analyzed using the General Meteorological Package (GEMPAK) utility (Koch et al. 1983) with parameters chosen to emphasize large mesoscale $(L>100 \mathrm{~km})$ features including frontal zones in which deep convection occurs.

Central to the analysis of convection initiation (CI), the subsequent UTLS gravity waves, and associated turbulence are PECAN radiosonde data from FP sites 
Surface Analysis and Maximum Column Radar Reflectivity
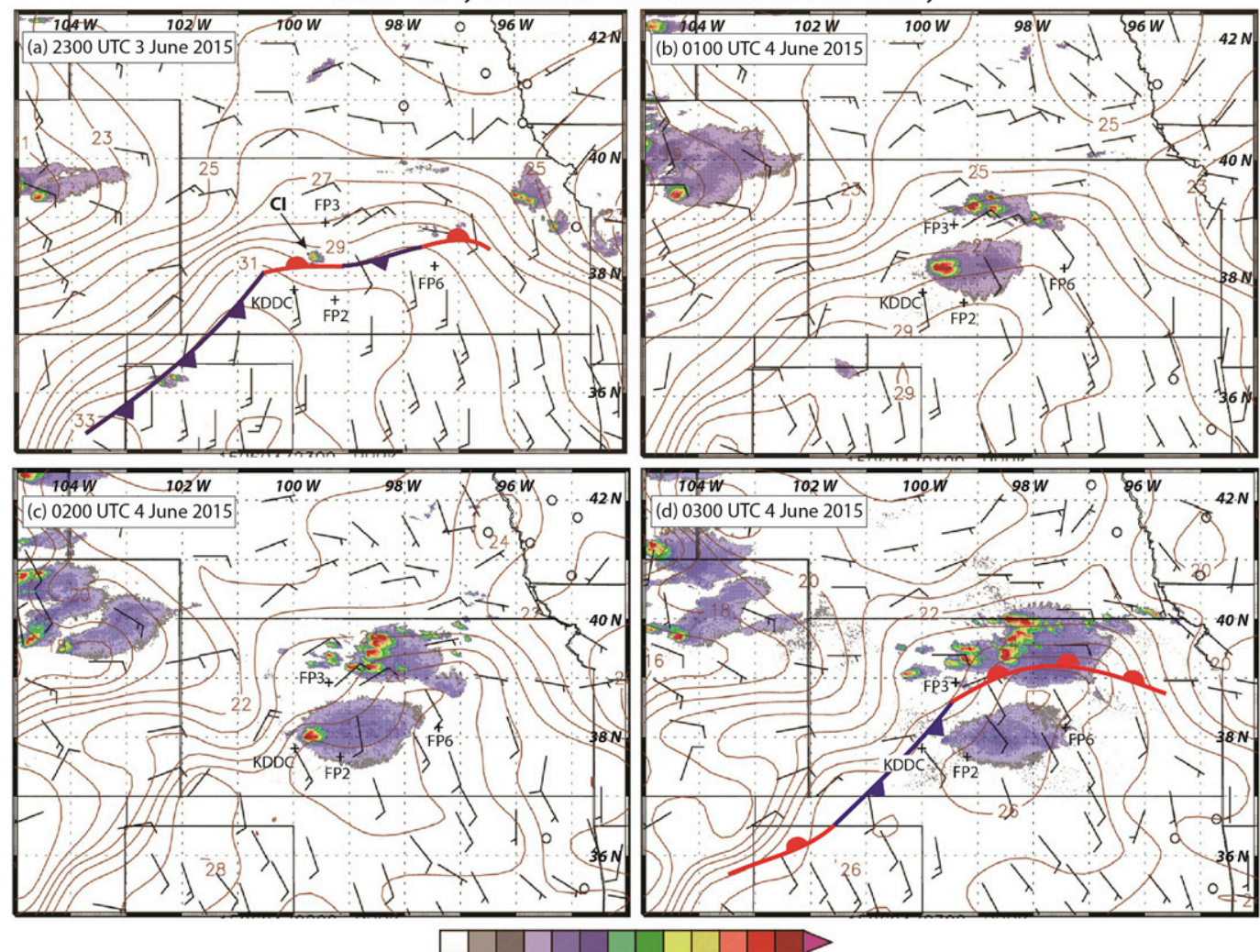

$-5051015202530354045505560$

MREF [dBZ]

FIG. 2. Surface winds, objectively analyzed surface temperature $\left(1^{\circ} \mathrm{C}\right.$ contour intervals $)$, and NEXRAD WSR-88D radar mosaics of maximum reflectivity in a vertical column at (a) 2300 UTC 3 Jun, (b) 0100 UTC 4 Jun, (c) 0200 UTC 4 Jun, and (d) 0300 UTC 4 Jun 2015. The cross symbols indicate locations of radiosonde data displayed or analyzed in Figs. 3, 4, 8, 9, and 10. The positions of surface fronts are subjectively analyzed in (a) and (d). Convection initiation (CI) for the storm of interest is marked by the arrow in (a). Winds follow the standard meteorological plotting convention of half barb $=5 \mathrm{kt}\left(\approx 2.5 \mathrm{~m} \mathrm{~s}^{-1}\right)$, full barb $=10 \mathrm{kt}\left(\approx 5 \mathrm{~m} \mathrm{~s}^{-1}\right)$, and pennant $=50 \mathrm{kt}\left(\approx 25 \mathrm{~m} \mathrm{~s}^{-1}\right)$.

(Fig. 1). The PECAN data consist of radiosondes having approximate 0000 and 0130 UTC 4 June 2015 launch times with launch locations at $37.61^{\circ}$ latitude, $-99.28^{\circ}$ longitude near Greensburg, Kansas (FP2; Vermeesch 2015); at $38.94^{\circ}$ latitude, $-99.57^{\circ}$ longitude near Hays, Kansas (FP3; Clark 2016); and at $38.14^{\circ}$ latitude, $-97.43^{\circ}$ longitude near Hesston, Kansas (FP6; Holdridge and Turner 2015). These data are supplemented by National Weather Service (NWS) radiosonde data from Dodge City, Kansas $\left(37.76^{\circ}\right.$ latitude, $-99.97^{\circ}$ longitude), launched at 2300 UTC 3 June 2015. Each of these soundings reaches the upper troposphere $(Z>8.5 \mathrm{~km} \mathrm{MSL})$ and lower stratosphere $(Z>13 \mathrm{~km} \mathrm{MSL})$ approximately 30 and $60 \mathrm{~min}$, respectively, after their launch from the surface. The radiosonde data are vertically interpolated to $100-\mathrm{m}$ levels (MSL) for examination of the thermodynamic environment supporting deep convection (section 3a) and quantities that influence UTLS gravity wave propagation and turbulence including the Scorer parameter and gradient Richardson number (section $3 \mathrm{~b}$ ).

\section{Observations}

\section{a. Storm initiation and evolution}

The storm that produced gravity waves in its downstream anvil (Fig. 1) initiated around 2300 UTC (1800 local daylight time) 3 June along a quasi-stationary surface front (Fig. 2a).

Radiosondes surrounding the storm were available to help characterize its environment near or slightly after its initiation. The KDDC (Dodge City, Kansas) NWS operational sounding that launched at 2300 UTC 3 June (Fig. 3a) and the FP2 PECAN sounding that launched one hour later (Fig. 3b) were located south of the quasistationary front. These soundings each had large convective available potential energy (CAPE) of $\sim 2500 \mathrm{~J} \mathrm{~kg}^{-1}$ 

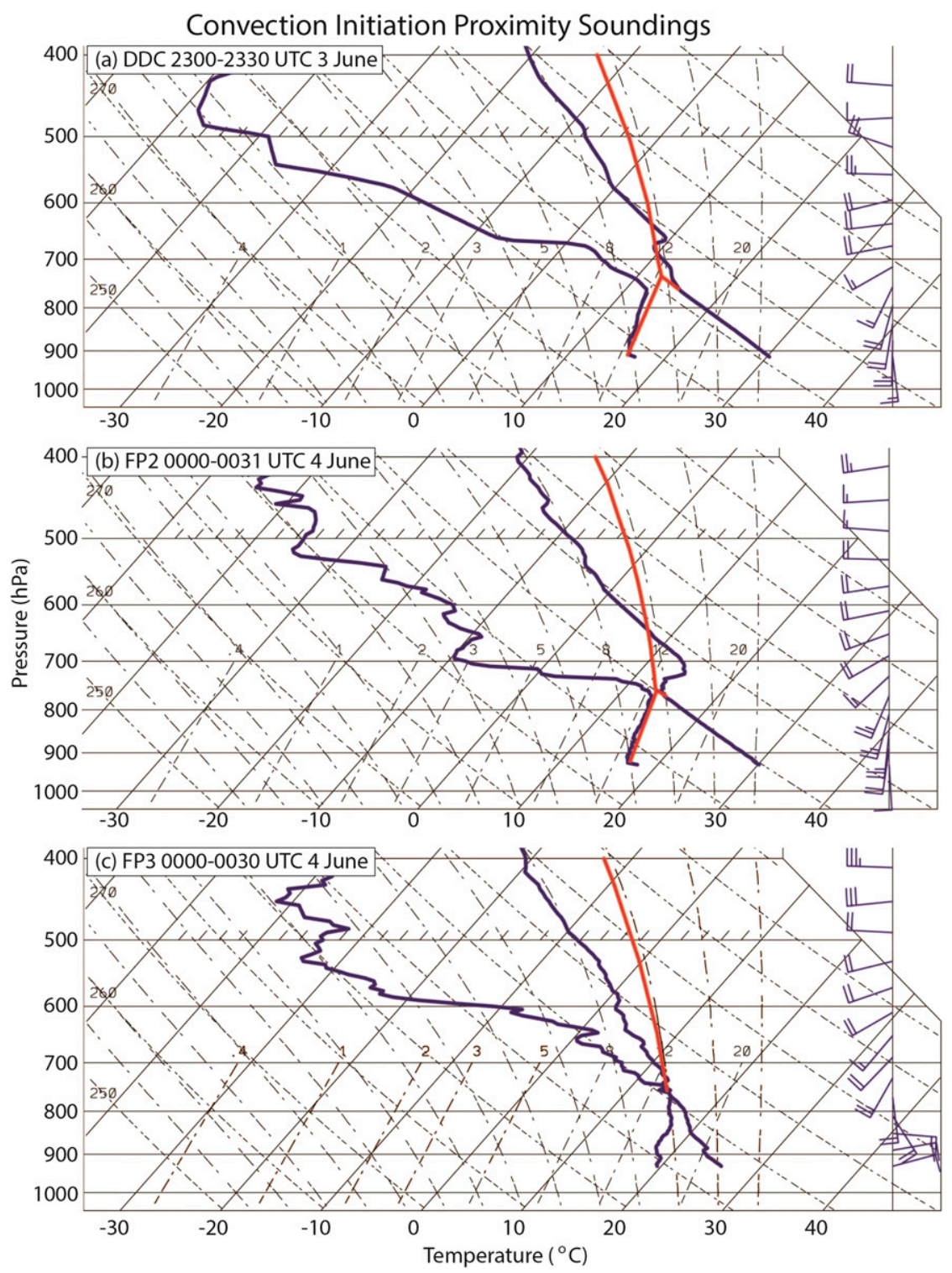

FIG. 3. Radiosonde data from (a) KDDC (Dodge City, KS), (b) FP2 (Greensburg, KS), and (c) FP3 (Ellis, KS) at the indicated times. The red curves represent theoretical parcel ascent paths for 50-hPa-deep averaged parcels having the least convective inhibition (CIN). The locations of radiosonde launch sites relative to deep convection are given in Figs. 1, 2, and 5. Wind plotting convention as in Fig. 2.

but also a $\sim 1-\mathrm{km}$-deep layer of convective inhibition (CIN) located above the PBL for air parcels having the mean mixing ratio and virtual potential temperature of the lowest $50 \mathrm{hPa}$. The CIN ranges from $11 \mathrm{~J} \mathrm{~kg}^{-1}$ at KDDC (Fig. 3a) to $34 \mathrm{~J} \mathrm{~kg}^{-1}$ at FP2 (Fig. 3b). The modest but significant CIN suggests the importance of horizontal convergence along the surface front in initiation of the storm (Fig. 2a), which is signified by the narrow band of cumulus congestus extending southwestward from the storm during its early development evident in the 1-km visible satellite imagery (cf. Figs. 1a,b).

Shortly after the formation of the isolated storm along the quasi-stationary front, a mesoscale cluster of storms forms farther north within the surface baroclinic zone (Figs. 2b,c). The 0000 UTC 4 June FP3 sounding (Fig. 3c) is most representative of the environment supporting the initiation of these storms and has large CAPE of $\sim 3000 \mathrm{~J} \mathrm{~kg}^{-1}$, but there is also substantial CIN of $41 \mathrm{~J} \mathrm{~kg}^{-1}$ for a $50-\mathrm{hPa}$-deep surface-based air parcel. 


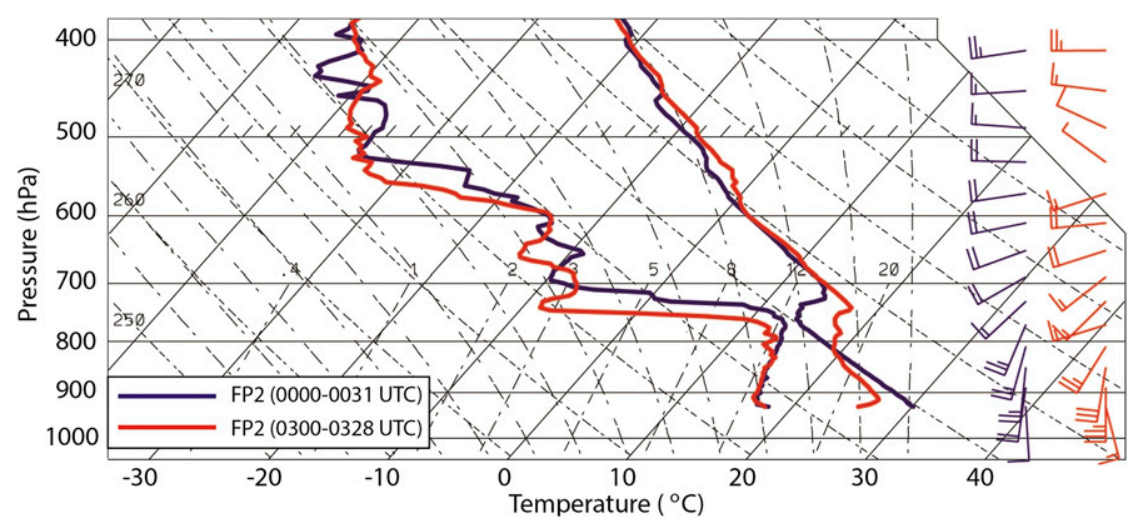

FIG. 4. Evolution of temperature, dewpoint, and horizontal winds at the PECAN FP2

(Greensburg, KS) radiosonde site during the life cycle of the large southern storm in Fig. 2.

However, unlike south of the surface front at KDDC and FP2, an elevated moist absolutely unstable layer (MAUL; Bryan and Fritsch 2000) is evident from 780 to $740 \mathrm{hPa}$ (Fig. 3c). The flow in this elevated layer that is more favorable for $\mathrm{CI}$ is from the southwest (Fig. 2c), supporting the later initiation of the west-east-oriented band of convection north of FP3 (Fig. 2b).

The more isolated storm of interest that initiated earlier along the surface stationary front (Fig. 2a) maintained a persistent core of intense radar reflectivity at its western (upstream) edge for 3 hours while exhibiting $3.3 \mathrm{~m} \mathrm{~s}^{-1}$ motion from $5^{\circ}$ azimuth (Figs. 2a-c). This slow, approximately southward, storm motion contrasts significantly with the pressure-weighted mean flow in the cloud-bearing layer $(750-150 \mathrm{hPa})$ of $12.4 \mathrm{~m} \mathrm{~s}^{-1}$ from $265^{\circ}$ azimuth based on average environmental conditions above the PBL from the 2300 UTC 3 June KDDC and 0000 UTC 4 June FP3 soundings (Figs. 2a,b).

Significant propagation relative to the mean flow is one of the hallmarks of isolated supercell storms, and is explained by Rotunno and Klemp (1982) to be influenced by vertical pressure gradients associated with strong environmental vertical shear. The observed storm motion compares more closely with, but is slower and significantly to the right of $5.1 \mathrm{~m} \mathrm{~s}^{-1}$ from the $317^{\circ}$ azimuth predicted from a composite of the 2300 UTC KDDC and 0000 UTC FP3 soundings (not shown) using Bunkers et al. (2000) empirical formula based on a large sample of right-moving supercells. This suggests that motion of the isolated southern storm (Figs. 2a-c) could be governed by a combination of supercell dynamics and effects of forcing along the quasi-stationary surface front.

During the evening the quasi-stationary front moves northward as a warm front and coincides with the rapid dissipation of the southern storm after 0200 UTC (Figs. 2c,d). The rapid decay of the storm is consistent with the evolution in the 0000 and 0300 UTC FP2 soundings (Fig. 4), which is characterized by substantial warming directly above the PBL that appears related to subsidence south of the warm front. These events resulted in the increase of CIN for 50-hPa-averaged surface-based air parcels from 34 to $163 \mathrm{~J} \mathrm{~kg}^{-1}$ at FP2 during this 3 -h period.

Meanwhile the complex of newer storms north of FP3 becomes more widespread during the late evening as the warm front moves northward during the decay of the original isolated storm (Figs. 2c,d). This convection organizes into a new MCS along the Kansas-Nebraska border by late evening (Fig. 5) and persists overnight (not shown). In the remainder of the paper, we concentrate on the UTLS environment supporting the gravity waves in the anvil of the earlier more isolated storm.

\section{b. Trapped waves and their environment in the downstream anvil}

The position of the intense reflectivity core of this storm (Figs. 2b,c) coincides in visible satellite imagery with persistent overshooting convection at the west end of a much larger cloud mass expanding downstream toward the east-southeast (Fig. 1). Comparison with 4-km thermal infrared (IR) imagery reveals that the downstream cloud mass is cold with temperatures near of $\sim-60^{\circ} \mathrm{C}$ (Fig. 5), and is thus indicative of a UTLS anvil.

The visible anvil (Figs. 1b-d) has the overall shape of a bow wave that is confined to a wedge. In this regard, the anvil has some similarities with previous studies that emphasize ship wave signatures in the atmosphere (e.g., Sharman and Wurtele 1983; Wang et al. 2010). However, in the current case the shorter wavelength waves within the anvil are not stationary, and appear to be generated by transient overshooting updrafts.

The wavelike undulations emanating from the area of convective overshooting (Fig. 1) have horizontal 

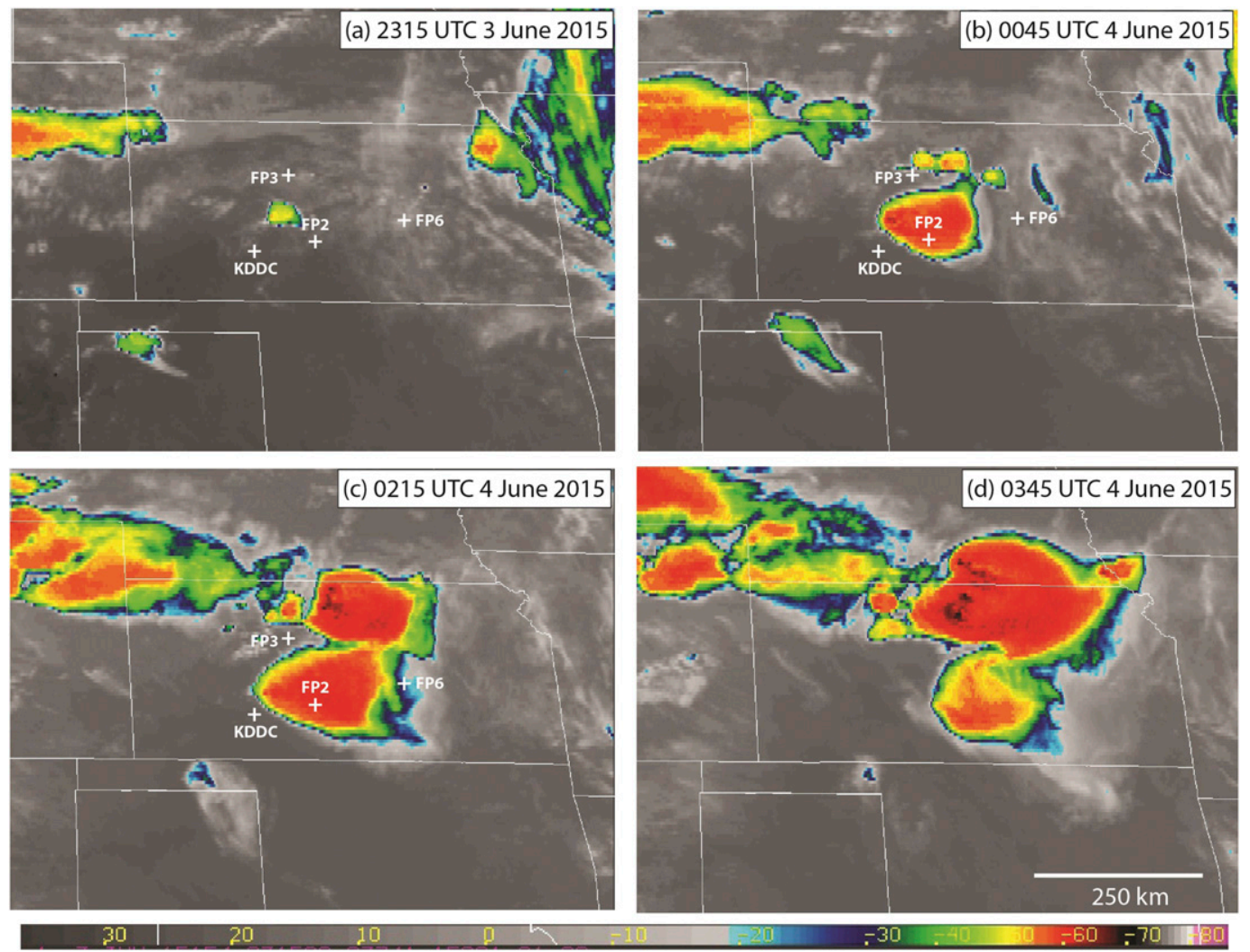

FIG. 5. GOES-14's 4-km pixel resolution thermal IR brightness temperature (color scale in ${ }^{\circ} \mathrm{C}$ ) at (a) 2315 UTC 3 Jun, (b) 0045 UTC 4 Jun, (c) 0215 UTC 4 Jun, and (d) 0345 UTC 4 Jun 2015. The cross symbols indicate locations of radiosonde data displayed or analyzed in Figs. 3, 4, 8, 9, and 10.

wavelengths of approximately $\lambda \approx 6-8 \mathrm{~km}$. Their approximate ground-relative phase speed of $c \approx 35 \mathrm{~m} \mathrm{~s}^{-1}$ from $290^{\circ}$ azimuth was estimated from animations of the 1-min visible satellite imagery during 2345 UTC 3 June (Fig. 1a) to 0130 UTC 4 June (Fig. 1d). In these animations the individual wavelike cloud features progress eastsoutheast through the overall anvil cloud, which being influenced by horizontal advection in the UTLS outflow jet expands outward at a slower rate of $\approx 25 \mathrm{~m} \mathrm{~s}^{-1}$. There are also more spatially confined wavelike cloud features along the upstream (western) edge of the convective overshooting, where there were earlier in situ reports of moderate turbulence (Fig. 1b). These upwind wavelike features are nearly stationary relative to the area of convective overshooting and are most pronounced in visible imagery near sunset (Fig. 1d).

Prior to the onset of the deep convection from which the gravity waves developed, the High-Resolution Rapid Refresh (HRRR) model (Smith et al. 2008) analysis shows contrasting upper-tropospheric airstreams across Kansas and northern Oklahoma (Fig. 6). The region west of $-100^{\circ}$ longitude is located in the exit region of a neartropopause jet streak and has westerly flow at $200 \mathrm{hPa}$, whereas the fixed PECAN sounding network in central Kansas is influenced by southerly flow on the west side of an upper-tropospheric anticyclone (Fig. 6a). The uppertropospheric anticyclone is a manifestation of outflow from an earlier nocturnal MCS over western Missouri at 2100 UTC 3 June, where there is near ice saturation at $250 \mathrm{hPa}$ (Fig. 6b).

A turbulence encounter occurring much later with in situ EDR values consistent with light and moderate turbulence ranging from 0.06 to $0.20 \mathrm{~m}^{2 / 3} \mathrm{~s}^{-1}$ is displayed at the downstream anvil edge in nearly synchronous visible satellite imagery (Fig. 7). Two PECAN soundings including FP2 within the anvil core $\sim 50 \mathrm{~km}$ from the upwind overshooting top, and FP6 at the downstream anvil edge (Fig. 7) were launched at 0130 UTC 4 June and reached the $\sim 11 \mathrm{~km}$ MSL $[36000 \mathrm{ft}(\sim 11 \mathrm{~km})]$ altitude of the turbulence reports $\sim 35-40 \mathrm{~min}$ later. These soundings are indicated by the red thermodynamic and wind profiles in Fig. 8, where they are compared with the earlier 0000 UTC 4 June FP3 sounding, which is representative of upstream environmental conditions.

In contrast to the upstream environmental conditions at FP3, both the FP2 (Fig. 8a) and FP6 (Fig. 8b) soundings 
HRRR Analysis Upper-Tropospheric Conditions at 2100 UTC 3 June 2015
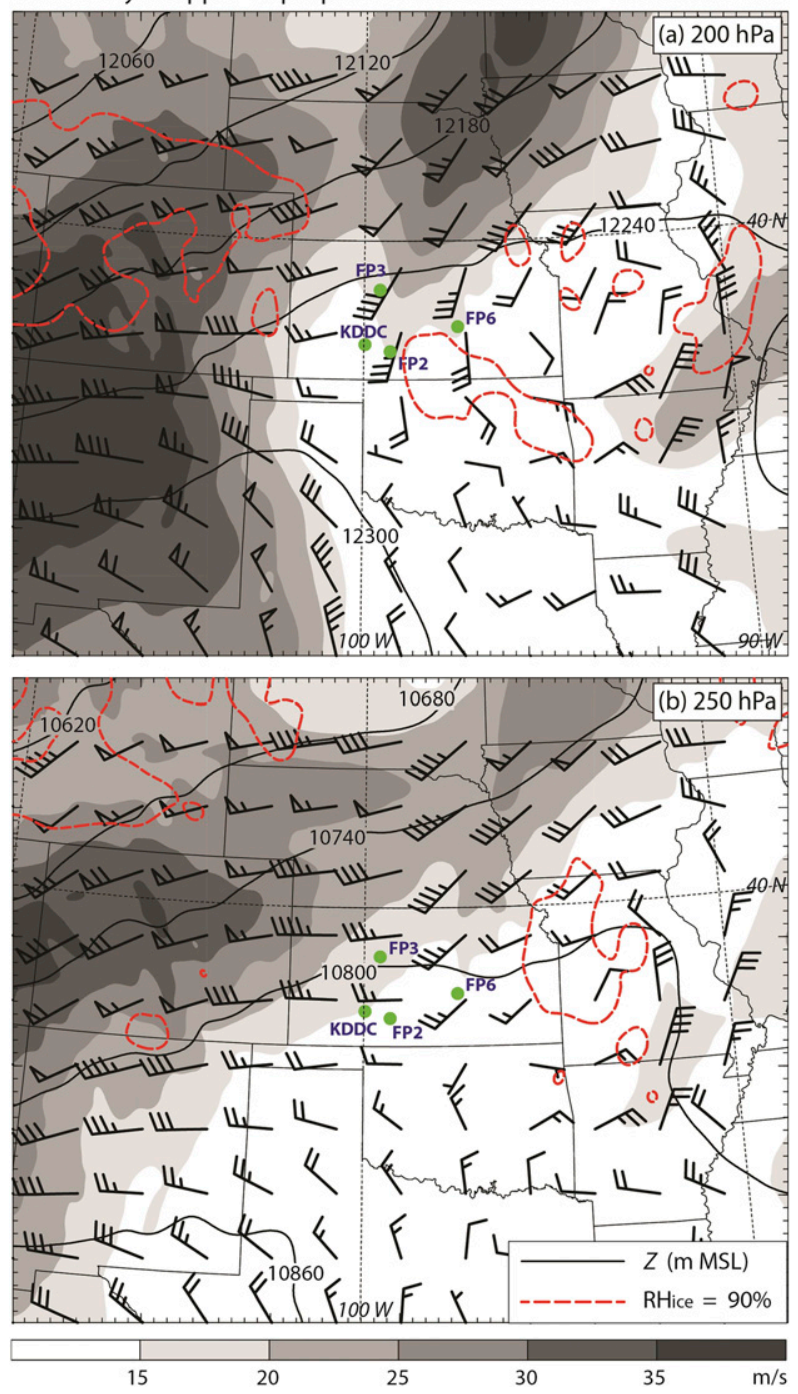

FIG. 6. High-Resolution Rapid Refresh (HRRR) model analysis (0-h forecast) from 2100 UTC 3 Jun 2015 at (a) 200 and (b) $250 \mathrm{hPa}$. Geopotential heights are contoured in 60-m intervals (black lines), isotachs are shaded, and regions having relative humidity with respect to ice equal to or exceeding $90 \%$ are enclosed by the dashed red contours. The green circles indicate locations of radiosonde data displayed or analyzed in Figs. 3, 4, 8, 9, and 10. Wind plotting convention as in Fig. 2.

have moist UTLS layers close to or exceeding ice saturation with increased flow along $\sim 290^{\circ}-110^{\circ}$ azimuth near the top of these layers. This signifies an outflow jet near the top of the ice anvil oriented in the approximate direction of the horizontal wave propagation (cf. Fig. 7). Comparison of the FP2 (Fig. 8a) and FP6 (Fig. 8b) soundings suggests a denser and significantly deeper ice anvil at FP2 located closer to the parent overshooting convection. There are also differences in the horizontal wind profiles from these two locations, with a southwesterly wind direction in the lower third of the UTLS moist layer at FP6 compared to westerlies throughout the moist layer at FP2. This likely reflects some continuing influence of the residual anticyclonic outflow circulation (Fig. 6) from the earlier decaying MCS at the more eastward location of FP6. However, these differences between the soundings occur $1-2 \mathrm{~km}$ beneath the prominent outflow associated with the newer isolated overshooting deep convection.

In both anvil soundings, the $\sim 30 \mathrm{~m} \mathrm{~s}^{-1}$ west-northwesterly jet is located at $13.7 \mathrm{~km} \mathrm{MSL}(\sim 160 \mathrm{hPa})$, which is close to or slightly above the level of neutral buoyancy (LNB). This indicates that the jet enhancement likely arises from divergent outflow detraining from the convective overshooting region being aligned along the approximate direction of the environmental wind.

Environmental factors contributing to the wave duct may be quantified using a simplified version of the Scorer parameter (e.g., Nappo 2002):

$$
l^{2}=\frac{N^{2}}{(U-c)^{2}}-\frac{d^{2} U / d z^{2}}{U-c},
$$

\section{Term 1 Term 2}

where $N^{2}=\left(g / \theta_{v}\right)\left(\partial \theta_{v} / \partial z\right)$ is the static stability, ${ }^{1}$ $c=35 \mathrm{~m} \mathrm{~s}^{-1}$ is the estimated ground-relative horizontal phase speed of the waves, and $U$ is the wind in the $290^{\circ}-110^{\circ}$ direction of horizontal wave propagation (cf. Fig. 1d). Using the WKB approximation, the vertical wavenumber for two-dimensional Boussinesq flow is $m^{2}=l^{2}-k^{2}$, where $k=2 \pi / \lambda$ is the horizontal wavenumber. Waves can vertically propagate when $m^{2}>0$, which requires $l^{2}>k^{2}$. Waves are evanescent (i.e., have vertical decay of their amplitude) at altitudes where $l^{2}<k^{2}$, and are often referred to as ducted or "trapped" at altitudes where $l^{2}-k^{2} \approx 0$.

The anvil profiles (Figs. 9a,b) and the upstream (Fig. 9c) and downstream (Fig. 9d) profiles each have multiple weak evanescent layers beneath $13 \mathrm{~km}$ where the magnitude of $l^{2}$ is small and $l^{2}<k^{2}$. A more significant and distinguishing characteristic of the anvil profiles are the strong evanescent layers with $l^{2} \ll 0$ beginning near $13.5 \mathrm{~km}$ MSL for FP2 (Fig. 9a) and at $13.3 \mathrm{~km}$ MSL for FP6 (Fig. 9b). These altitudes are immediately beneath jet maxima of $U \approx 30 \mathrm{~m} \mathrm{~s}^{-1}$, where $c-U$ is relatively small and the vertical wind shear becomes sharply more negative with height (i.e., $\left.d^{2} U / d z^{2} \ll 0\right)$ [term 2 of (1)], which contributes to wave trapping. Within the anvil core at FP2 (Fig. 9a), the wave trapping is also aided by small static stability $N^{2}$ within

\footnotetext{
${ }^{1}$ The static stability used in (1) closely approximates the moist static stability in the region of interest near the tropopause.
} 


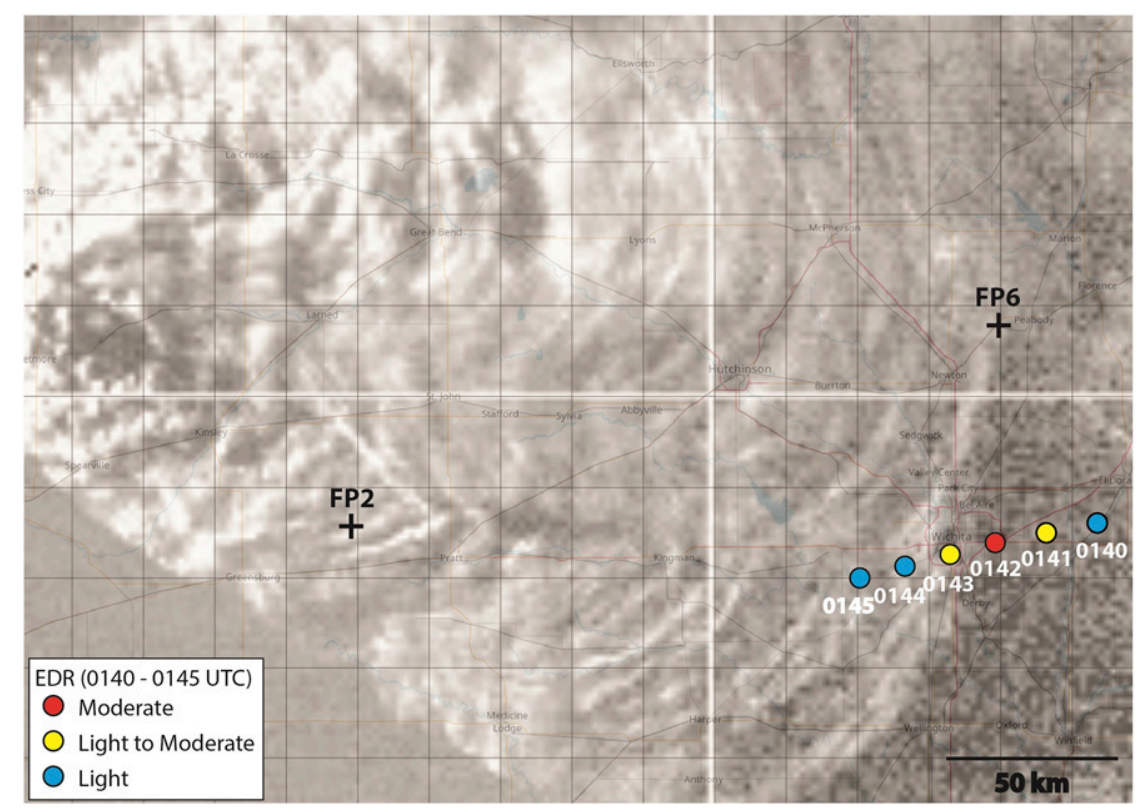

FIG. 7. GOES-14's 1-km pixel resolution imagery at 0142 UTC 4 Jun 2015. The 5-min flight track and in situ eddy dissipation rate (EDR) observations from a B-737 commercial airliner along its flight track at 36000 feet $(\sim 11 \mathrm{~km}$ MSL) are overlaid, where EDR values indicative of light and moderate turbulence have ranges of $0.05-0.20$ and $0.10-0.40 \mathrm{~m}^{2 / 3} \mathrm{~s}^{-1}$ [as in Lane and Sharman (2014)], respectively. The locations of the 0130 UTC FP2 and FP6 PECAN radiosonde launches, when they pass through the altitude of $11 \mathrm{~km}$ MSL approximately 25-30 min later (Fig. 8, red curves) are denoted by the cross symbols.

the jet [term 1 of (1)] associated with the near-neutral layer at the top of the anvil (Fig. 8a, red curves).

The $U$ profile for the earlier (0000 UTC) FP6 sounding (Fig. 9d) launched well before the outflow from the developing storm reaches this location (cf. Figs. 1a,b) differs from that of the upstream profile (Fig. 9c), owing to the residual circulation from the decayed MCS (Fig. 6) influencing the former. Nevertheless, this sounding has an $l^{2}$ profile (Fig. 9d) that is qualitatively similar to that of the upstream sounding (Fig. 9c) and both lack layers of large negative $l^{2}$ found in the anvil soundings (Figs. 9a,b).

The differences between the $l^{2}$ profiles within the anvil and those from either upstream or at the downstream anvil-edge location, but prior to outflow reaching that location, implies the importance of the convectively generated outflow jet in the local development of conditions favorable for significant wave trapping. This hypothesis is tested using sensitivity studies with a high-resolution numerical model in section 4.

As noted earlier, light and moderate turbulence was observed at several locations in the vicinity of gravity waves near the downstream anvil edge (Figs. 1c,d). The vertical locations of these turbulence reports are indicated by the green asterisks symbols in Fig. 10a.
Instability is possible in three-dimensional sheared flows when the gradient Richardson number,

$$
\mathrm{Ri}=N^{2} / S^{2},
$$

is $\leq 1$ (Miles 1986), where $S^{2}=(\partial u / \partial z)^{2}+(\partial v / \partial z)^{2}$. Several thin layers between 11.1 and $13.2 \mathrm{~km}$ MSL meet this criterion in the upstream environmental sounding, whereas $\mathrm{Ri} \leq 1$ is nearly continuous through the same $11.1-13.2 \mathrm{~km}$ MSL layer, and also in the $9.7-10.4 \mathrm{~km}$ MSL layer in the downstream anvil sounding (Fig. 10a). This indicates that while turbulence is possible in the upstream environment, it is much more likely in the region the influenced by convectively generated UTLS outflow.

For the sounding at the downstream anvil edge, the shaded layers in which the gradient Richardson number is smallest, $\mathrm{Ri}<0.5$, have either stronger vertical shear (11.1-11.7- and 13.1-13.3-km layers) or weaker static stability (12.1-12.4-km layer) than in the corresponding layers for the upstream environment sounding (Fig. 10b). Moreover, either vertical shear increases $\left(\Delta S^{2}>0\right)$ or static stability decreases $\left(\Delta N^{2}<0\right)$ dominate any less favorable changes to the other component of $\mathrm{Ri}$ in these $\mathrm{Ri}<0.5$ layers at the downstream anvil edge. The collocation of deeper layers with small 


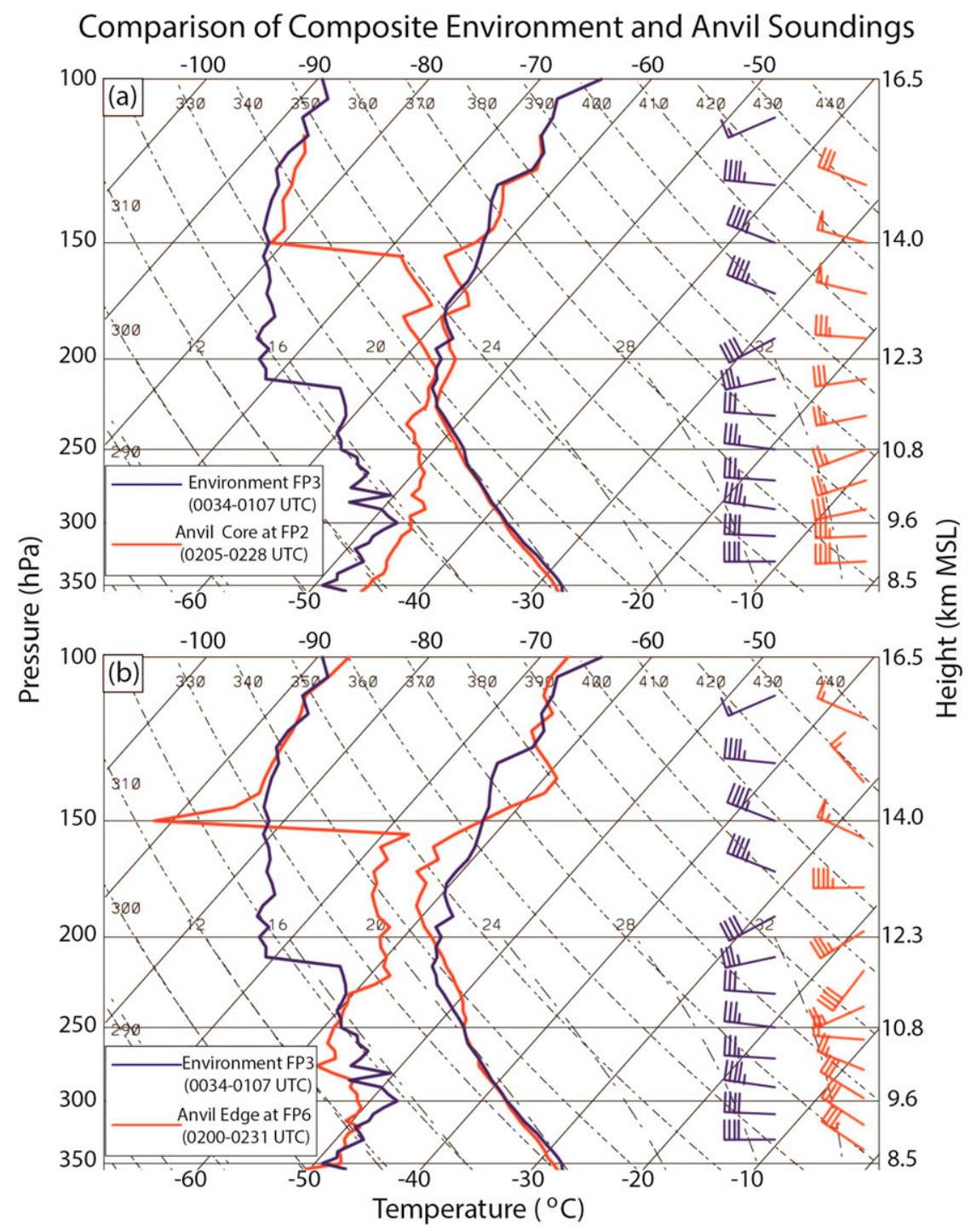

FIG. 8. UTLS part of thermodynamic and wind soundings from FP3 (Fig. 5b), launched at 0000 UTC 4 Jun (blue), from (a) FP2 launched at 0130 UTC 4 Jun (red), representative of conditions $\sim 50 \mathrm{~km}$ from upwind deep convection (Fig. 7), and from (b) FP6 launched at 0130 UTC 4 Jun (red), representative of conditions near the downstream anvil edge (Fig. 7). Wind plotting convention as in Fig. 2.

$\mathrm{Ri}$ with the trapped gravity waves suggests a possible role they may have in the development of turbulence. This possible connection is explored using numerical simulations in the next section.

\section{Numerical simulations}

\section{a. Numerical model and design of simulations}

Simulations were performed using the Advanced Research version of the Weather Research and Forecasting (ARW-WRF, version 3.8) Model (Skamarock and Klemp 2008). For the current simulations, the model has 82 vertical grid points with spacing that increases linearly from 60 to $240 \mathrm{~m}$ through the lowest $\sim 2 \mathrm{~km}$ AGL. From $\sim 2$ to $\sim 14 \mathrm{~km} \mathrm{AGL}$, the vertical spacing is approximately constant at $\sim 240 \mathrm{~m}$, and then increases linearly to $\sim 1200 \mathrm{~m}$ at the $20-\mathrm{hPa}(\sim 26.3 \mathrm{~km}$ MSL) model top. A 7-km-deep absorbing layer (Klemp et al. 2008) is used to damp spurious reflection of vertically propagating gravity waves off the rigid upper boundary of the model.

The control simulation discussed in this paper uses the Thompson et al. (2008) bulk microphysical parameterization. Other physical parameterizations include the Rapid Radiative Transfer Model (RRTM) 

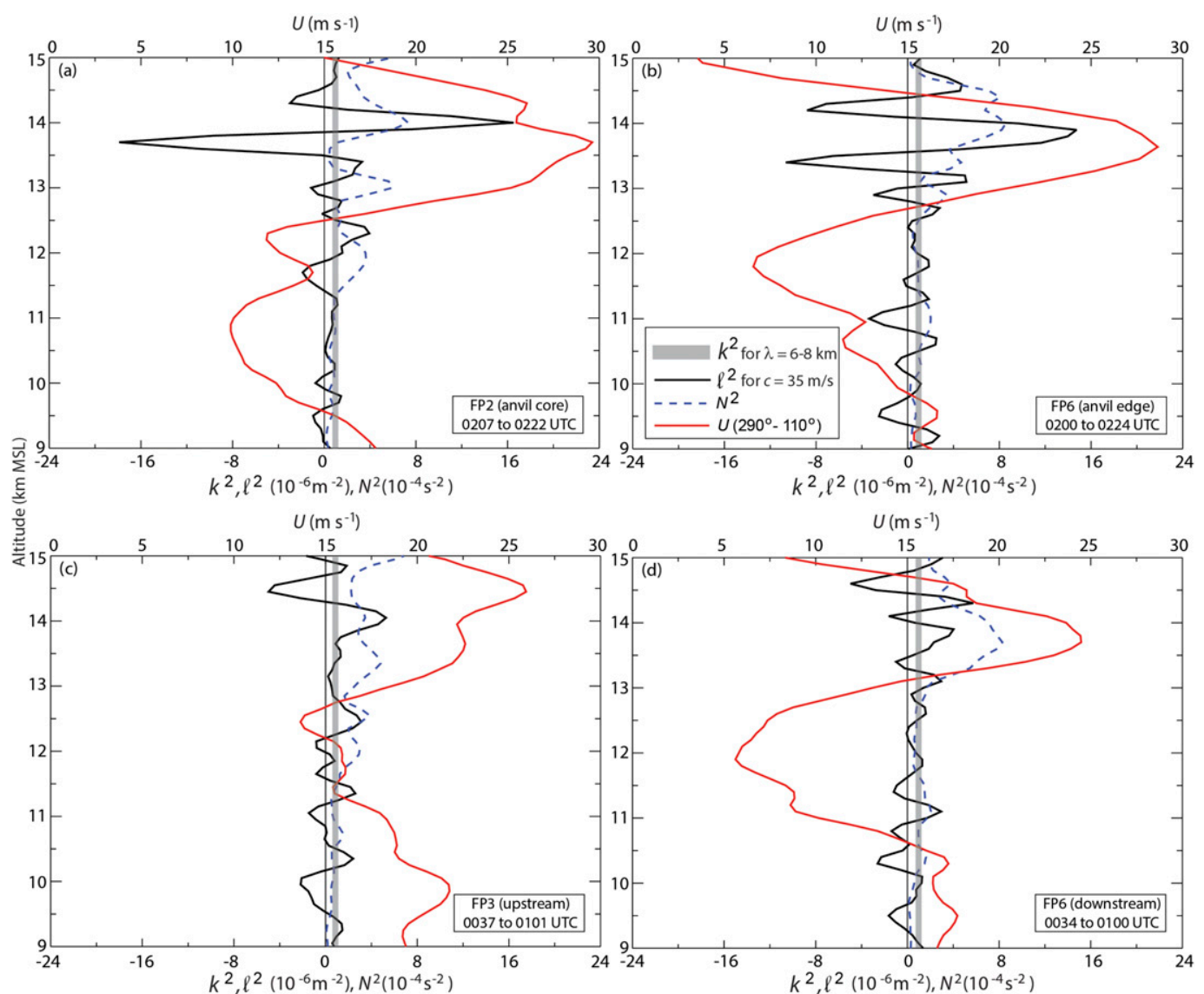

FIG. 9. UTLS vertical profiles of the Scorer parameter squared $\left[\ell^{2},(1)\right]$ using $c=35 \mathrm{~m} \mathrm{~s}^{-1}$, the Brunt-Väisälä frequency $\left(N^{2}\right)$, and the horizontal wind within the approximate plane of horizontal wave propagation $(U, \mathrm{cf}$. Fig. 7) from the (a) FP2 0130 UTC 4 Jun, (b) FP6 0130 UTC 4 Jun, (c) FP3 0000 UTC 4 Jun, and (d) FP6 0000 UTC 4 Jun 2015 PECAN radiosonde launches. The gray shading in each panel indicates the square of the horizontal wavenumber for $\lambda=6-8-\mathrm{km}$ waves inferred from the high-resolution visible satellite imagery (Fig. 1). (top) Vertical profiles that represent conditions close to (a) upwind deep convection in the anvil and (b) at the downstream anvil edge (Fig. 7). (bottom) Vertical profiles representative of conditions from the precursor environment (Fig. 5b) both (c) upstream and (d) downstream from the deep convection and its associated anvil.

longwave (Mlawer et al. 1997) and the Dudhia (1989) shortwave radiation schemes. The atmospheric model is coupled with the Noah land surface model (Ek et al. 2003) and utilizes the Mellor-Yamada-Janjić (MYJ) PBL scheme (Janjić 2001), which predicts turbulence kinetic energy (TKE) and governs the subgrid vertical mixing between model vertical levels both within and above the PBL. The TKE forcing in this parameterization is provided by shear production $[-\overline{w u}(\partial U / \partial z)-\overline{w v}(\partial V / \partial z)]$, buoyancy production $\left(\beta g \overline{w \theta_{\mathrm{lv}}}\right)$, and dissipation terms, where $\theta_{\mathrm{lv}}$ is the liquid water virtual potential temperature, $w$ is vertical velocity, $g$ is gravitational acceleration, and $\beta$ is an empirical constant. In these forcing terms the uppercase quantities are the gridresolved horizontal wind components and the lowercase quantities with overbars are the subgrid parameterized fluxes. The horizontal diffusion mixing coefficient is diagnosed from values of grid-scale horizontal deformation.

The simulations use initial and lateral boundary conditions from HRRR model analyses for a convectionallowing domain with $600 \times 500$ horizontal grid points having a horizontal spacing of $3 \mathrm{~km}$. This domain (Fig. 11) is initialized at 1200 UTC 3 June 2015 and integrated for $18 \mathrm{~h}$ until 0600 UTC 4 June 2015 . The ability of numerical models to properly simulate internal gravity waves is strongly dependent on horizontal resolution (e.g., Lane and Knievel 2005). Thus, we add a one-way interactive nest (dashed rectangle in Fig. 11) at 2100 UTC 3 June, approximately $2 \mathrm{~h}$ before observed initiation of the storm of interest. This nest has $750 \times$ 750 horizontal grid points with $600-\mathrm{m}$ spacing, and is integrated for $6 \mathrm{~h}$ ending at 0300 UTC 4 June, which 


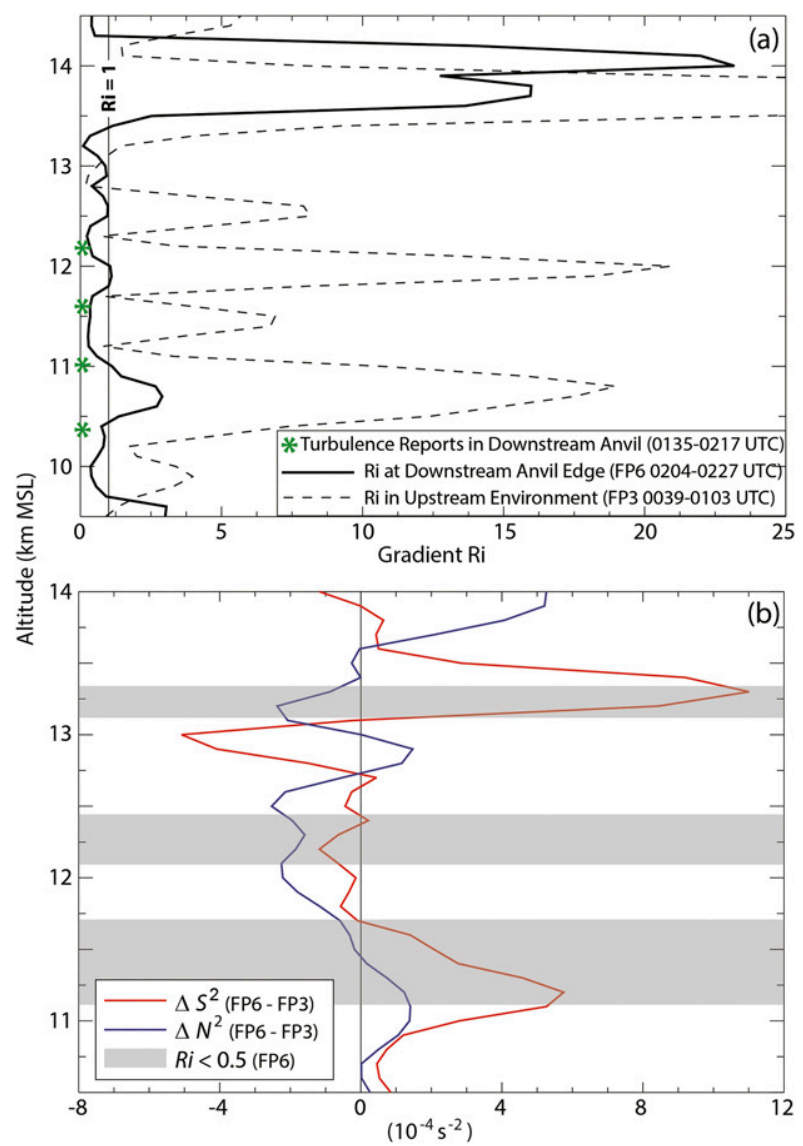

FIG. 10. UTLS vertical profiles of (a) the gradient Richardson number (Ri) from FP3 (dashed) and FP6 (solid) radiosonde launches at 0000 and 0130 UTC 4 Jun 2015, respectively, and (b) differences between these soundings in the numerator (blue curve) and denominator (red curve) of $\mathrm{Ri}$ [(2)]. The green asterisk symbols in (a) show the altitudes of turbulence reports shown in Fig. 1d and the light shading in (b) indicates layers where $\mathrm{Ri}<0.5$ for the FP6 radiosonde launched at 0130 UTC 4 Jun 2015.

coincides with the dissipation of the observed (southernmost) storm of interest (Figs. 2c,d).

Analysis of the PECAN radiosonde observations in the previous section suggested dependence of the vertical trapping of internal gravity waves on the convectively generated UTLS outflow. To further explore this possibility, we perform an additional simulation (termed "dry") that is identical to the control simulation except that all cloud microphysical processes are removed.

\section{b. Simulation results}

The CI occurs in the high-resolution $\Delta(x, y)=600-\mathrm{m}$ domain (D02) of the control simulation slightly before 2300 UTC 3 June (Fig. 12a), and is located approximately $50 \mathrm{~km}$ northwest of where it was observed (cf. Fig. 2a). The near-tropopause flow is westerly near this initiation but is southwesterly farther east (Fig. 12a),

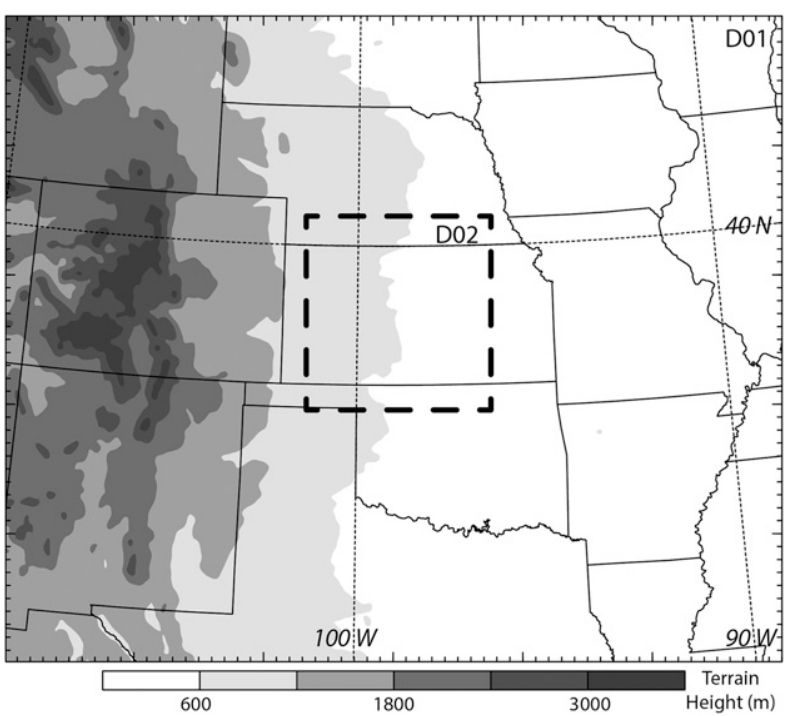

FIG. 11. Horizontal domain D01 (with $\Delta=3-\mathrm{km}$ horizontal grid spacing) and its one-way nest D02 (with $\Delta=600$-m horizontal grid spacing) used in the WRF simulations discussed in section 4 . The shading indicates a smoothed version of the surface elevations in D01.

owing to effects from the dissipating MCS, which is located outside of D02. As in the observations, the simulated storm undergoes rapid intensification and becomes a strong storm between FP3 and KDDC (Fig. 12b) during the next $60-90 \mathrm{~min}$, while moving slowly southward. During this intensification period, approximate flow stagnation occurs on the upwind side of the simulated storm while there are significant $\left(\sim 5-10 \mathrm{~m} \mathrm{~s}^{-1}\right)$ increases in the westerly flow on its downstream side (Fig. 12b).

Also similar to the observations, subsequent development of deep convection occurs north of FP3 (Fig. 12b), and becomes the dominant region of convection during the next few hours (Figs. 12c,d). However, the simulated initial (southern) storm dissipates 30-45 min earlier than the corresponding strong southern storm in the observations (cf. Figs. 2c,d).

A mesoscale band of near-tropopause TKE moves downstream from the higher-reflectivity deep convection region during the mature-to-dissipating stages of the simulated southern storm (Figs. 12c,d). Maximum values of TKE in the downstream 11-13 km MSL layer during 0100-0145 UTC are $5 \mathrm{~m}^{2} \mathrm{~s}^{-2}$, with local maxima more typically having values of $\sim 2 \mathrm{~m}^{2} \mathrm{~s}^{-2}$. Consistent with observed turbulence reports (Fig. 1b), enhanced TKE also occurs upstream of the simulated storms, but does not become located as far from cores of maximum reflectivity as on the downstream side (Figs. 12c,d).

In the simulations, neither the downstream cloud edge nor significant TKE reach the location of FP6, owing to both the initiation of the simulated storm $\sim 50 \mathrm{~km}$ 
D02 Maximum Relectivity, $12.8 \mathrm{~km}$ Winds, and $12.3 \mathrm{~km}$ TKE
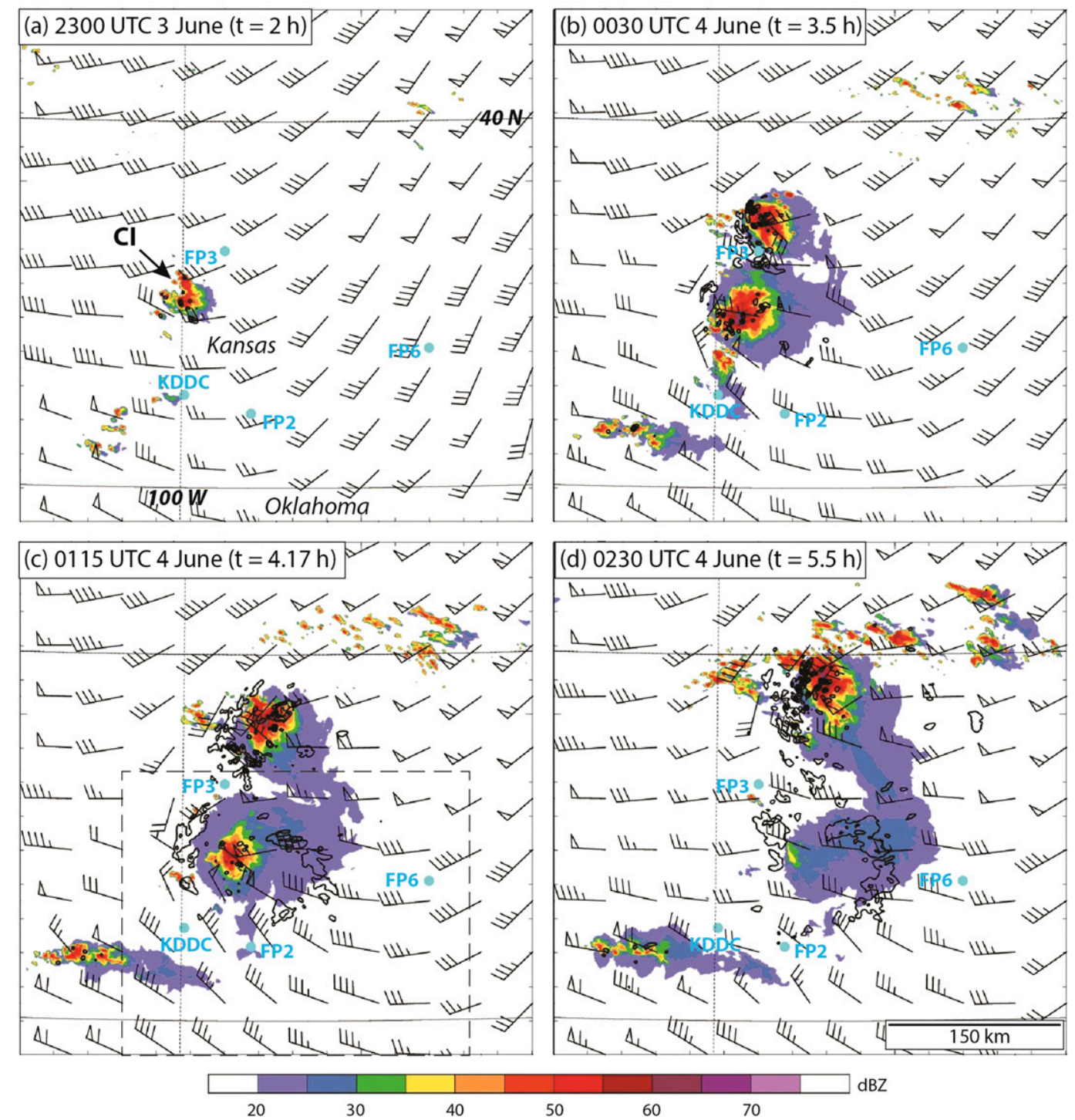

FIG. 12. Model-derived column maximum radar reflectivity (color shading), $12.8 \mathrm{~km}$ MSL horizontal winds and $12.3 \mathrm{~km}$ MSL turbulence kinetic energy $\left(1 \mathrm{~m}^{2} \mathrm{~s}^{-2}\right.$ contour intervals, starting at $\left.0.5 \mathrm{~m}^{2} \mathrm{~s}^{-2}\right)$ for the one-way nested D02 domain (Fig. 11) at (a) 2300 UTC 3 Jun, (b) 0030 UTC 4 Jun, (c) 0115 UTC 4 Jun, and (d) 0230 UTC 4 Jun 2015. The cyan circles indicate locations of the annotated radiosonde launch sites, and the dashed inset in (c) indicates the location of the display region in Fig. 13. Wind plotting convention as in Fig. 2.

northwest of where initiation is observed and more rapid storm dissipation than was observed. However, the spatial relationship of the simulated turbulence to the simulated deep convection and downstream anvil cloud edge is qualitatively similar to what is observed, though its intensity is somewhat greater.

Following Sharman et al. (2012) EDR is approximated from the simulated TKE using $\varepsilon \approx 0.84(\mathrm{TKE})^{3 / 2} / \Delta$. Assuming the length scale $\Delta$ corresponds to the approximate model vertical grid spacing of $240 \mathrm{~m}$ yields
EDR values of 0.21 and 0.34 for the TKE values of 2 and $5 \mathrm{~m}^{2} \mathrm{~s}^{-2}$, respectively. These EDR values are consistent with moderate and moderate-to-severe turbulence intensities (Lane and Sharman 2014). Recall, that several instances of light and moderate turbulence were reported near the anvil cloud edge in the vicinity of FP6 (Figs. 1d, 7). However, vertical cross sections presented later in this section indicate that the majority of the observed turbulence reports were from somewhat lower altitudes than those with maximum simulated TKE. 
Figure 13 presents the $11 \mathrm{~km}$ MSL simulated vertical velocity and its relationship to the approximate simulated anvil during 0110-0130 UTC 4 June for the dashed inset region in Fig. 12c surrounding the southern storm. Wavelike structures in the vertical velocity field that are broadly similar to the waves in the visible satellite imagery (Figs. 1c,d) extend east-southeast from a core of stronger upward motion near the center of the storm to the approximate cloud edge at both 0110 (Fig. 13a) and 0130 UTC (Fig. 13b).

The alternating pattern of updrafts and downdrafts is evident through a 3-4-km deep layer within the downstream anvil from $x \sim 60-130 \mathrm{~km}$ in a vertical cross section (Fig. 14a) along transect AD2-BD2 of Fig. 13a at 0110 UTC. These vertical velocity perturbations have amplitudes of $\sim 0.5-1.5 \mathrm{~m} \mathrm{~s}^{-1}$ and their lack of vertical tilt, together with their approximate $90^{\circ}$ phase shift from the horizontal locations of corresponding potential temperature perturbations in the stable layer immediately beneath the outflow layer at the top of the anvil (cf. Fig. 15a), are characteristic of vertically trapped internal gravity waves. The same vertical cross section from 20 min later at 0130 UTC (Fig. 14b) shows a continuation of trapped gravity waves within and beneath the southeastward-expanding anvil with shortest horizontal wavelengths of $6-8 \mathrm{~km}$ that are similar to those in the visible satellite data (Fig. 1d). By this time, the strong overshooting deep convection near $x=15-30 \mathrm{~km} 20 \mathrm{~min}$ earlier (Fig. 14a) had weakened appreciably (Fig. 14b), which coincided with development of a stratospheric mesoscale gravity wave (evident in potential temperature) above the subsiding cloud top near $x=15-50 \mathrm{~km}$.

We now assess the role of the upstream deep convection on the vertical trapping of the upper-tropospheric gravity waves beneath the top of the downstream anvil by comparing the control simulation with the dry simulation (section 4a). The simulated profiles at the anvil edge for the control (Fig. 16b) and dry (Fig. 16c) simulations have a single deep and weak evanescent layer with $k^{2}>l^{2}$ beneath $\sim 12.5 \mathrm{~km}$ MSL in contrast to the multiple shallower weak evanescent layers in corresponding observations (cf. Figs. 9b,d). However, the strong evanescent layer between 13 and $13.6 \mathrm{~km}$ MSL in the control simulation (Fig. 16b) compared to only weak evanescence in a portion of this layer for only the shortest waves (i.e., largest $k^{2}$ ) in the dry simulation (Fig. 16c) is broadly consistent with corresponding comparisons between observations at the downstream anvil edge (Fig. 9b) and at the same location $90 \mathrm{~min}$ earlier prior to the arrival of the convective outflow (Fig. 9d).

For gravity wave forcing in the $l^{2}>k^{2}$ layer from 12.2 to $12.7 \mathrm{~km}$ MSL of the control simulation (Fig. 16b) located near or slightly above the tropopause in the upstream
D02 Control 11-km MSL Vertical Velocity and 12.8-km MSL Cloud Boundary
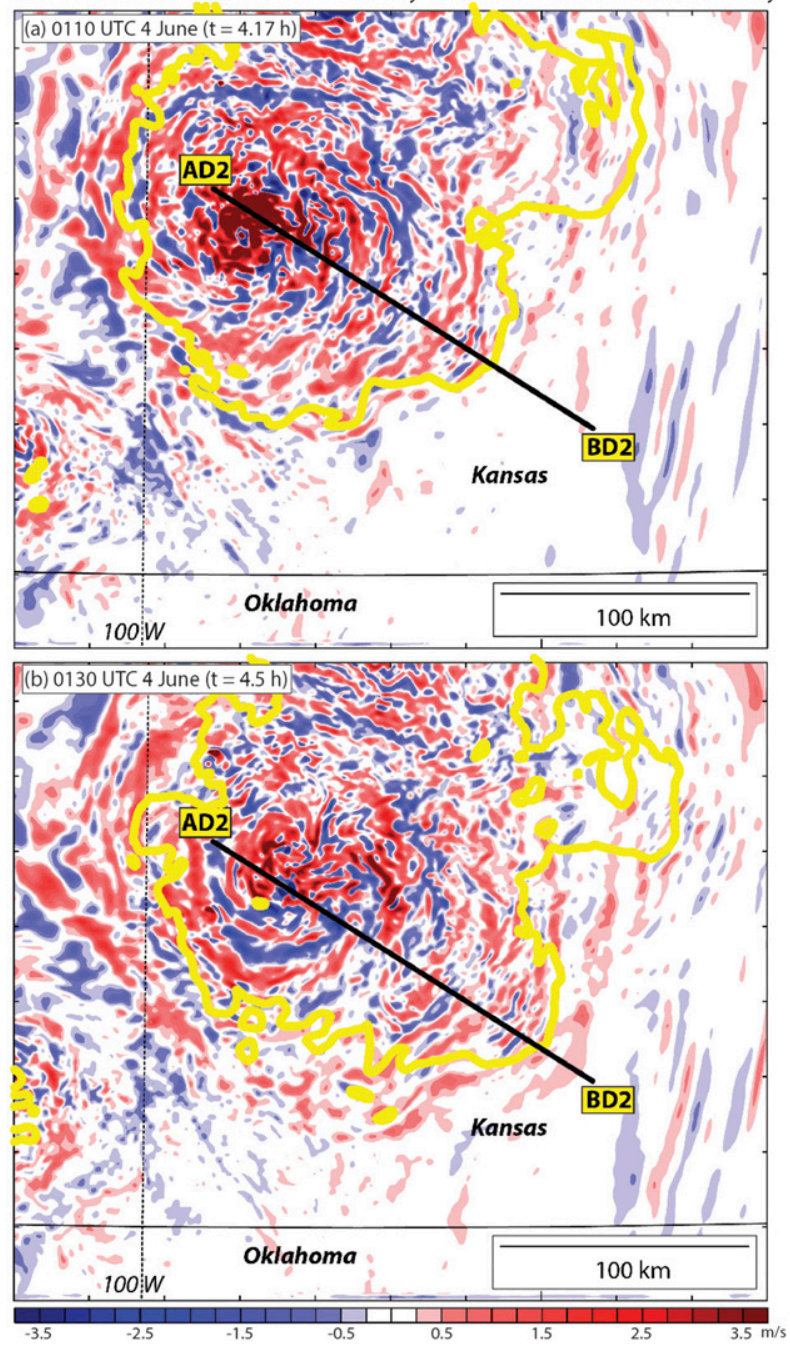

FIG. 13. Simulated $11 \mathrm{~km}$ MSL vertical velocity (color shading) and $12.8 \mathrm{~km}$ MSL $0.1 \mathrm{~g} \mathrm{~kg}^{-1}$ aggregate cloud water, cloud ice, and snow mixing ratio (single bold yellow contour) for the highresolution nest D02 at (a) 0110 UTC 4 Jun and (b) 0130 UTC 4 Jun 2015 for the location shown by the dashed inset in Fig. 12c. The transect AD2-BD2 indicates the location of vertical cross sections displayed in Figs. 14, 15, and 18.

sounding (cf. Fig. 8, blue curves), upward-propagating waves would be abruptly trapped by the strong evanescent layer beginning near $13 \mathrm{~km}$ MSL (Fig. 16b). However, downward-propagating waves could decay more slowly (i.e., "leak") into the much weaker evanescent layer whose top is situated slightly above $12 \mathrm{~km}$ MSL (Fig. 16b). This scenario is consistent with the layer of trapped gravity wave vertical velocity perturbations that extends from approximately 10 to $13 \mathrm{~km}$ MSL at the $x=150 \mathrm{~km}$ location (Fig. 14b) of the Fig. 16b vertical profile.

The (control - dry) wind difference along the cross section (oriented in the direction of horizontal wave 


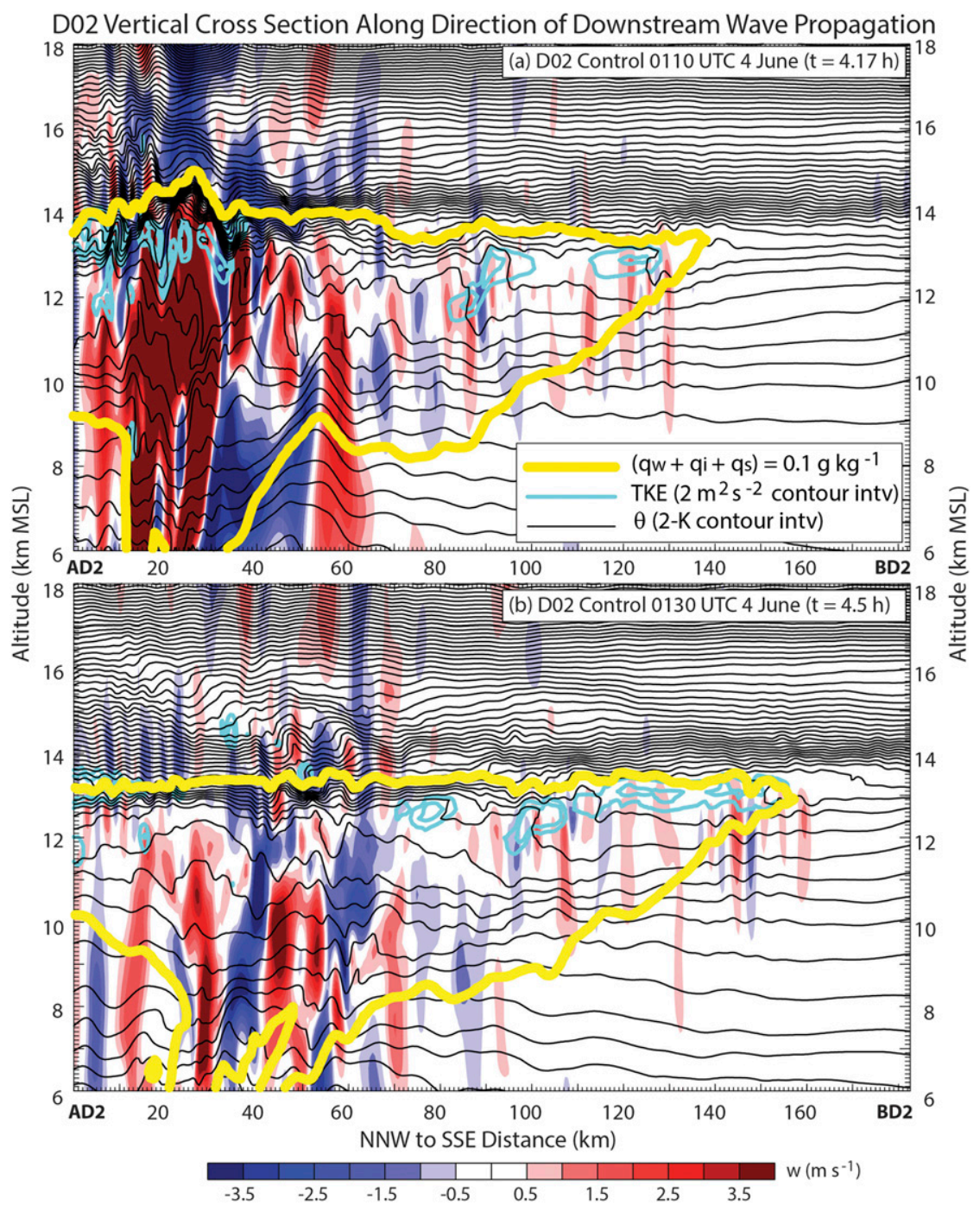

FIG. 14. Simulated vertical velocity (color shading), potential temperature (2-K contour intervals), turbulence kinetic energy $\left(2 \mathrm{~m}^{2} \mathrm{~s}^{-2}\right.$ contour interval starting at $\left.0.5 \mathrm{~m}^{2} \mathrm{~s}^{-2}\right)$, and $0.1 \mathrm{~g} \mathrm{~kg}^{-1}$ aggregate cloud water, cloud ice, and snow mixing ratio (single bold yellow contour) along transect AD2-BD2 at (a) 0110 UTC 4 Jun in Fig. 13a and (b) 0130 UTC 4 Jun 2015 in Fig. 13b.

propagation) from the control simulation (Fig. 15a) indicates large convectively induced flow enhancements that are maximized near the top of the anvil (red contours). These flow enhancements (Fig. 15a) both strengthen and sharpen the jet, which is evident from comparing wind profiles from the control and dry simulations at the downstream anvil edge of the control simulation (Fig. 16a). Here, increases in jet intensity and curvature $\left(d^{2} U / d z^{2} \ll 0\right)$ through term 2 on the righthand side of (1) are the primary contributor to $l^{2} \ll 0$, which favors wave trapping near $13 \mathrm{~km}$ MSL in the control simulation (Fig. 16b). This comparison between the control and dry simulations further supports the observational evidence from PECAN radiosonde data (section 3) that UTLS jet changes resulting from upstream deep convection were of primary importance to the gravity wave trapping in the anvil.

To address the question of whether the trapped gravity waves influence the development of turbulence, it is instructive to examine the evolution of potential temperature and TKE within the simulated downstream anvil. The control simulation cross section shows isentropes overturning with patches of TKE at 0110 UTC (Fig. 14a) becoming more widespread at 0130 UTC (Fig. 14b) near the top of the trapped gravity waves. This thermodynamic destabilization is a mesoscale effect 


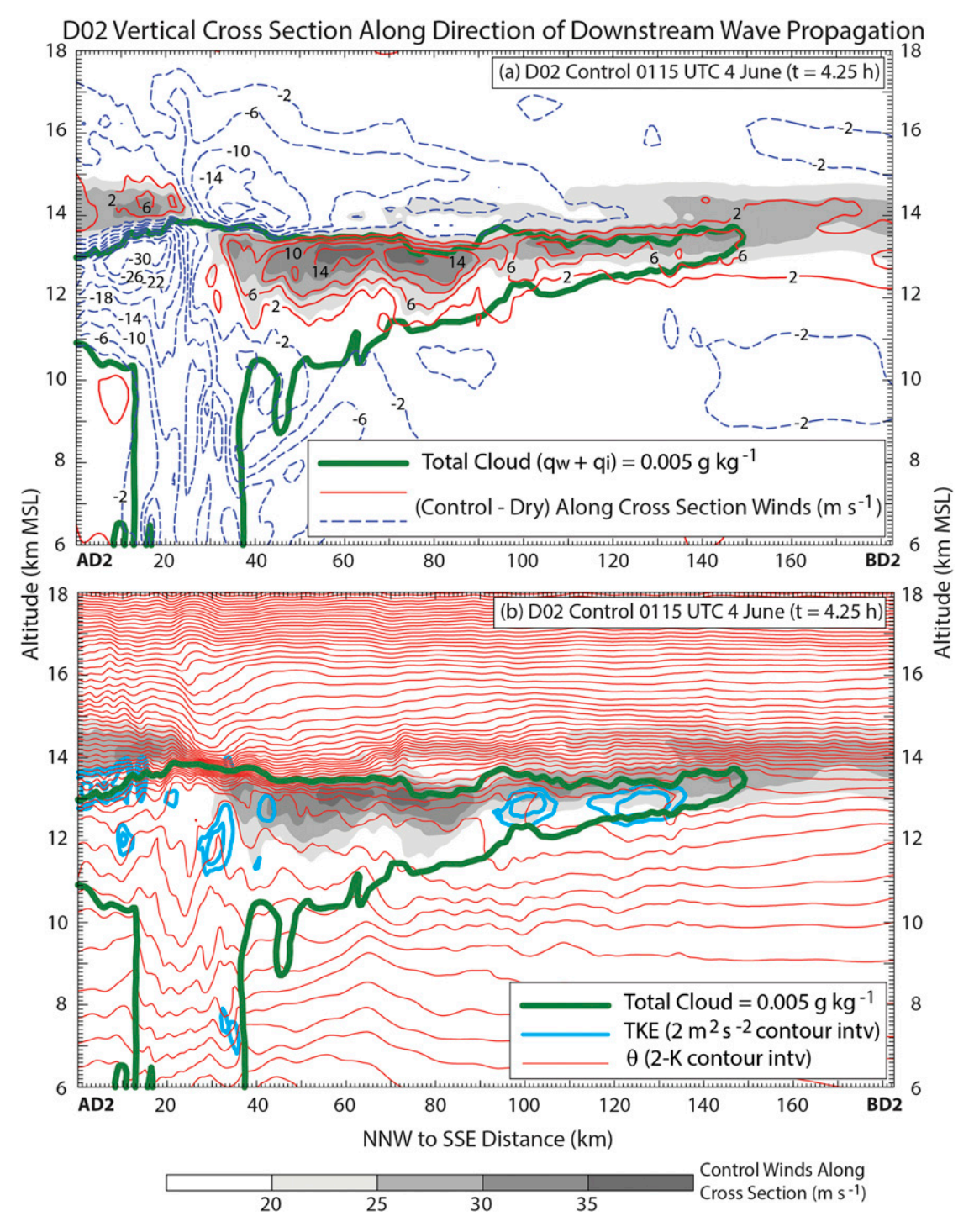

FIG. 15. Vertical cross sections along the location of transects AD2-BD2 of Fig. 13, which are horizontally averaged for a distance of $6 \mathrm{~km}$ normal to the cross section at 0115 UTC 4 Jun. Aggregate cloud water and cloud ice mixing ratio of $0.005 \mathrm{~g} \mathrm{~kg}^{-1}$ (single bold green contour) and cross-sectional parallel horizontal winds for the control simulation (gray shading) and (a) control - dry cross-sectional parallel horizontal winds [red solid (blue dashed) contours indicate flow toward (away from) BD2], and (b) potential temperature (red contours, 2-K intervals) and turbulence kinetic energy (cyan contours, $2 \mathrm{~m}^{2} \mathrm{~s}^{-2}$ intervals starting at $0.5 \mathrm{~m}^{2} \mathrm{~s}^{-2}$ ) for the control simulation.

occurring over the entire outer portion of the anvil (Fig. 15b), which has been previously illustrated for larger simulated MCS anvils (e.g., Lane et al. 2012, their Fig. 6). Using budget calculations of approximate moist static stability, Trier and Sharman (2009) attributed the mesoscale destabilization to differential horizontal advection of temperature in the vertical shear layer beneath the outflow jet. Trier et al. (2010) added that such destabilization at the outer edge of MCS anvils is enhanced by cloud radiative processes.
The coarser-resolution $\Delta(x, y)=3 \mathrm{~km}$ domain of the control simulation (D01) has reflectivity and UTLS outflow structures (Fig. 17a) that are qualitatively similar to those within the $\Delta(x, y)=600$-m nest (Fig. 12c). Because of the coarse resolution, the short-wavelength trapped gravity waves beneath the top of the anvil in Fig. 14a are not evident in a vertical cross section (Fig. 17b) through an analogous portion of the storm (see transect location in Fig. 17a). However, overturning of the isentropes with a mesoscale region of significant 
Conditions at Control Anvil Edge in Control (red) and Dry (blue) Runs
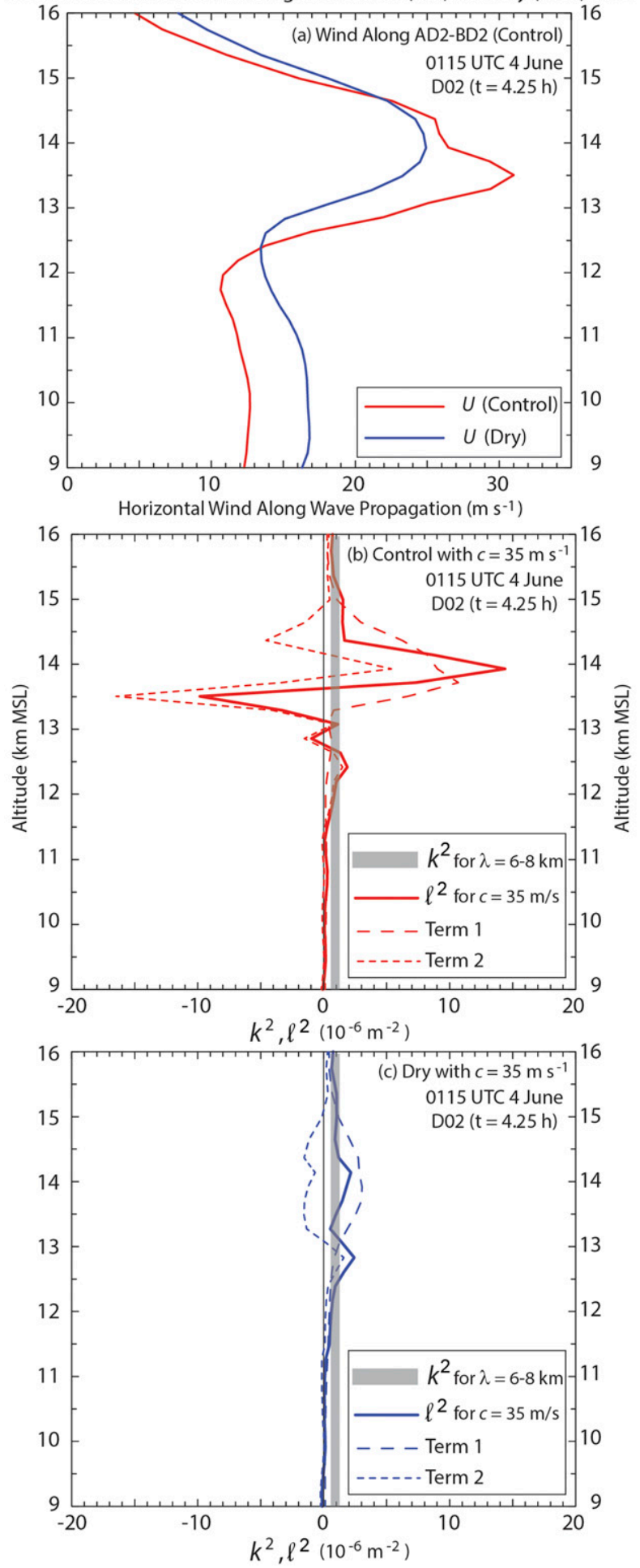

FIG. 16. Vertical profiles at $x=150 \mathrm{~km}$ in Figs. 15a and 15b of (a) horizontal winds in the direction of horizontal wave propagation along transect AD2-BD2 in Fig. 13a for the control (red) and dry simulations (blue), and Scorer parameter squared [(1)] for the (b) control and (c) dry simulations. Gray shading in each panel indicates the square of the horizontal wavenumber for the shortest wavelength $(\lambda=6-8 \mathrm{~km})$ simulated gravity waves in D02.
TKE in the outer anvil region, which is similar to that which occurs in the much higher-resolution nest (Fig. 14a) suggests that the trapped gravity waves may not be essential to the development of turbulence.

The differential advection associated with the enhanced vertical shear in the outflow coincides with a steepening of the isentropes (Fig. 17b, $x=85-105 \mathrm{~km}$ ) along the downshear edge of a mesoscale $\theta$ minimum (Fig. 17b, $x=$ $40-95 \mathrm{~km}$ ) within the anvil. The 0045-0115 UTC timeaveraged vertical difference of horizontal wind in the $11.4-12.8 \mathrm{~km}$ MSL layer horizontally averaged over the dashed inset of Fig. $17 \mathrm{~b}$ is $\Delta U=10.4 \mathrm{~m} \mathrm{~s}^{-1}$ (cf. upper and lower arrows in the Fig. 17b inset). Assuming that the horizontal advection in this $11.4-12.8 \mathrm{~km}$ MSL layer is dominated by that occurring in the direction of cross section orientation, the $\Delta t=30$-min change in lapse rate $(\Delta \theta / \Delta z)$ due to this advection may be approximated by

$$
\frac{\partial}{\partial t}\left(\frac{\Delta \theta}{\Delta z}\right) \Delta t \approx \frac{\partial}{\partial z}\left(-U \frac{\Delta \theta}{\Delta x}\right) \Delta t .
$$

Substituting an estimated $12.1 \mathrm{~km}$ MSL potential temperature gradient across the dashed region of Fig. 17b $\left(\Delta \theta / \Delta x \approx 0.1 \mathrm{~K} \mathrm{~km}^{-1}\right)$ into (3), yields a corresponding estimate of 30-min lapse rate change due to differential advection of $-1.34 \mathrm{~K} \mathrm{~km}^{-1}$, which compares well with the simulated $30-\mathrm{min}$ lapse rate change of $-1.46 \mathrm{~K} \mathrm{~km}^{-1}$ at its center $(x=95 \mathrm{~km})$. By 0115 UTC the $11.4-12.8 \mathrm{~km}$ MSL lapse rate at $x=95 \mathrm{~km}$ is near neutral with $\Delta \theta / \Delta z=0.62 \mathrm{~K} \mathrm{~km}^{-1}$ (Fig. 17b). The nearly vertical isentropic surfaces overturn farther downstream (Fig. 17b, $x=105-135 \mathrm{~km}$ ), where they have had longer exposure to the enhanced vertical shear in the outflow. This process results in static instability and generation of parameterized TKE in the outer anvil (Fig. 17b).

In the higher-resolution nest, a $\sim 75-\mathrm{km}$-long continuous layer with moist gradient Richardson number (Durran and Klemp 1982) $\mathrm{Ri} \leq 0.25$ is evident in the outer downstream anvil within the vertical shear layer beneath the jet maximum (Fig. 18a). Toward the edge of the anvil, more localized areas of static instability $(\mathrm{Ri}<0)$ occur directly above the potential temperature maxima associated with prominent trapped waves from $x=135$ to $160 \mathrm{~km}$ (Fig. 18b). In this way, the current simulations suggest that short-wavelength trapped waves can help localize regions of shallow convective overturning supporting turbulence within a larger region destabilized by mesoscale processes occurring in the outflow emanating from upstream deep convection.

\section{Summary and discussion}

In this study we have examined the development of vertically trapped short-wavelength $(\lambda \approx 6-8 \mathrm{~km})$ internal 
Domain 1 Control at 0115 UTC 4 June $(t=13.25 \mathrm{~h})$
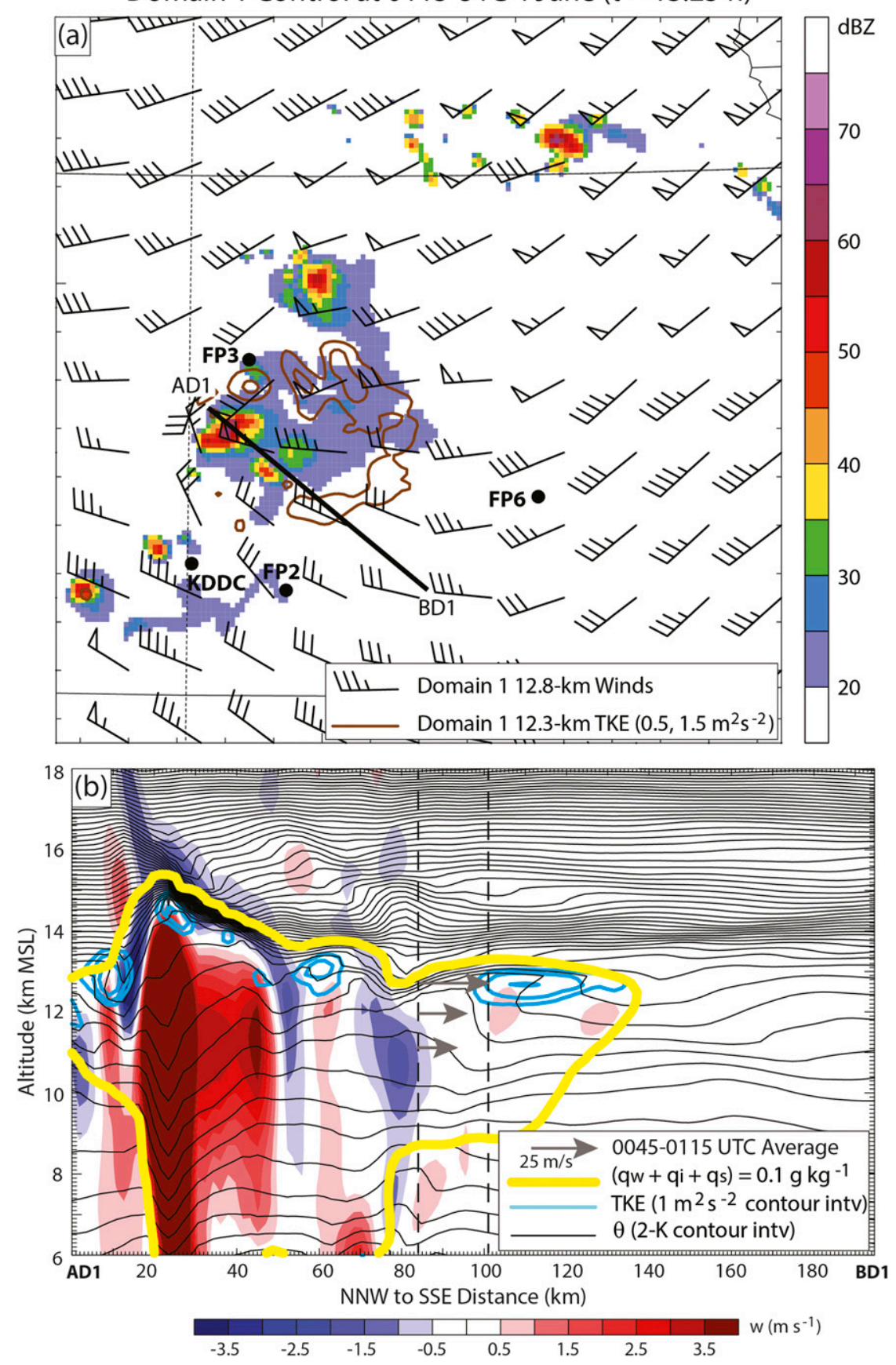

FIG. 17. (a) As in Fig. 12c, but for a similar size section of the low-resolution $(\Delta=3 \mathrm{~km})$ domain D01 (Fig. 11). Wind plotting convention as in Fig. 2. (b) As in Fig. 14a, but within domain D01 along transect AD1-BD1 of (a) at 0115 UTC 4 Jun 2015. The dashed vertical lines indicate the location of the 30-min time average during 0045-0115 UTC 4 Jun of the horizontal winds parallel to the cross section, which are indicated by the gray arrow symbols.

gravity waves within a large $\sim 200-\mathrm{km}$ downstream UTLS anvil emanating from a nearly stationary isolated thunderstorm observed during the PECAN field experiment over the central United States. The detection of these waves was facilitated by the fortuitous occurrence of the storm within the swath of 1-min highresolution GOES-14 visible satellite imagery having $1-\mathrm{km}$ pixel resolution. 


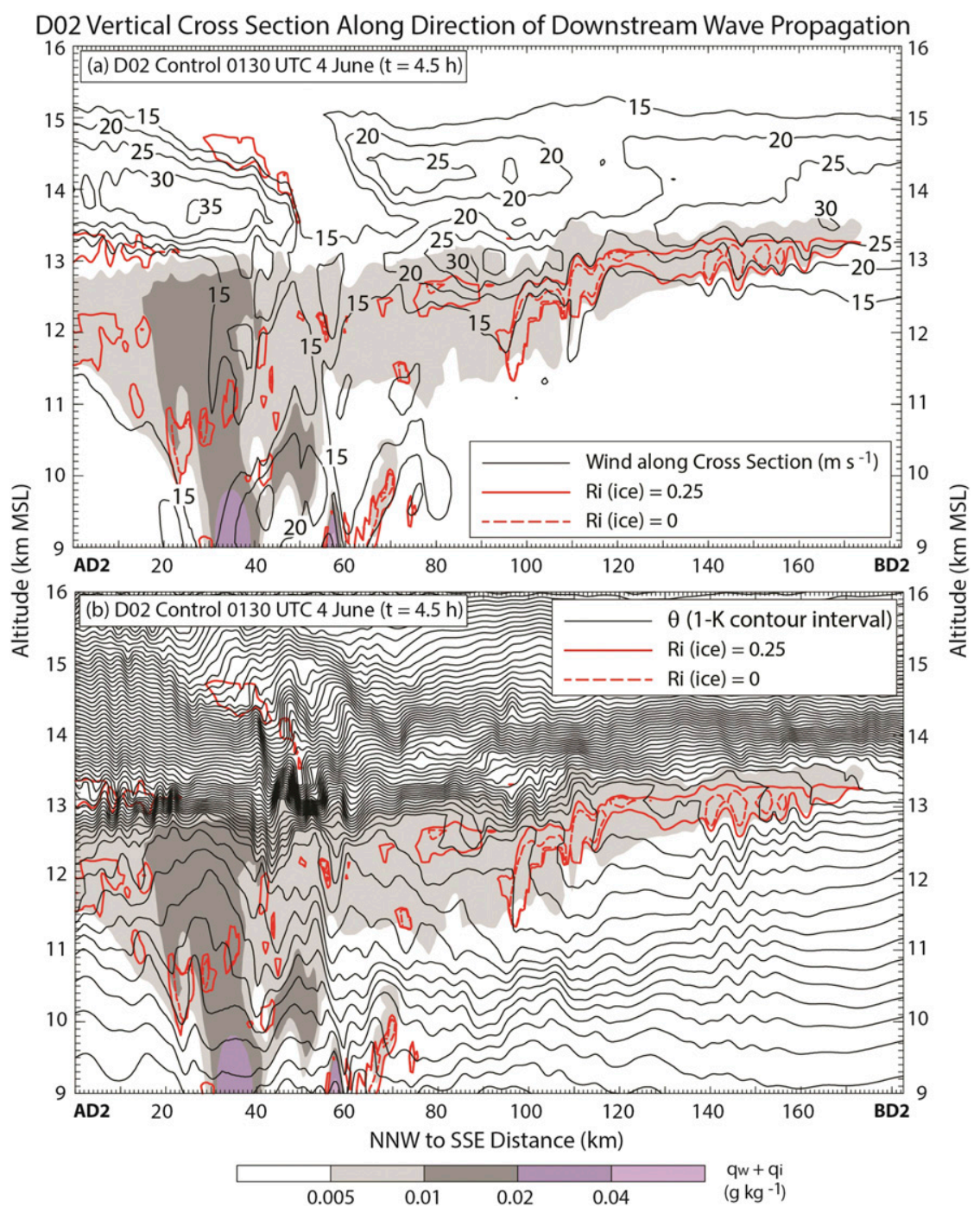

FIG. 18. Vertical cross sections along transect AD2-BD2 of Fig. 13b of total condensate (color shading), gradient Richardson number $\leq 0.25$ (solid red contours) and $\leq 0$ (dashed red contours) accounting for cloud and ice, and (a) horizontal winds from AD2 to BD2 (5 m s ${ }^{-1}$ contour interval, starting at $15 \mathrm{~m} \mathrm{~s}^{-1}$ ), and (b) potential temperature (1-K contour interval).

Special radiosonde data available during PECAN allowed examination of how the divergent UTLS outflow from the storm modified both the vertical profile of horizontal wind and static stability along the direction of horizontal wave propagation. Scorer parameter calculations using these data revealed a wave duct that allowed vertical trapping near the altitude of the outflow jet both within the core of the anvil $\sim 50 \mathrm{~km}$ from the center of the overshooting deep convection, and near the downstream edge of the anvil, located much farther from the deep convection. Comparisons with corresponding calculations from nearby PECAN soundings not directly affected by the UTLS outflow from the storm suggested that this outflow was the primary contributor to the wave trapping. This aspect was further supported by additional comparisons of Scorer parameter calculations from the downstream anvil edge in a full-physics high-resolution WRF Model simulation with corresponding calculations in a sensitivity simulation where cloud microphysical processes were withheld. The dependence of the vertical trapping of waves near the tropopause on mesoscale storm-induced UTLS outflow in this observed and simulated case supports the idealized modeling results of Zovko-Rajak and Lane (2014), where trapped convective gravity waves occurred in an environment with no initial vertical shear near the tropopause.

Past research has suggested that horizontally propagating gravity waves can locally reduce the gradient 
Richardson number in environments already susceptible to turbulence to values that permit turbulence due to shearing or static instabilities (e.g., Fovell et al. 2007; Lane et al. 2012). In the current case, light and moderate turbulence was reported by commercial airliners both close to and upstream of the overshooting deep convection, and more frequently near the downstream anvil edge located much farther from the parent deep convection. Gradient Richardson number Ri calculations using the PECAN radiosonde data revealed a $\sim 2.5-\mathrm{km}$-deep layer extending from $\sim 1 \mathrm{~km}$ below the base of the anvil $(\sim 11 \mathrm{~km})$ to the approximate anvil top $(\sim 13.5 \mathrm{~km}$ MSL $)$ with $\mathrm{Ri} \leq 1$ supporting turbulence at the downstream edge, whereas an earlier upstream sounding had average $\mathrm{Ri}$ through an identical layer that was much less conducive to turbulence (Fig. 10a).

Possible linkages between the gravity waves and turbulence were explored using both a high-resolution $[\Delta(x, y)=600-\mathrm{m}$ horizontal grid spacing $]$ control simulation and a coarser-resolution $[\Delta(x, y)=3-\mathrm{km}$ grid spacing] simulation that was still sufficient for explicit simulation of deep convection. The control simulation successfully simulated the short-wavelength internal gravity waves, which were vertically trapped at the top of the thin $\sim 1-\mathrm{km}$-deep downstream outer anvil cloud ice layer that marked the convective outflow, and extended a few kilometers beneath this layer. Conditions within the top of the simulated downstream anvil edge (12.5-13.5 km MSL) contained the most intense turbulence, which was aided by mesoscale thermodynamic destabilization near the top of the layer of trapped gravity waves.

The simulated thermodynamic destabilization was in turn influenced by differential advection associated with the strong vertical shear beneath the mesoscale outflow jet. Interestingly, similar thermodynamic destabilization was also evident in the low-resolution simulation that was unable to resolve the short-wavelength gravity waves. However, the precise locations of static instability in the outer anvil of the high-resolution control simulation were in phase with the trapped gravity wave activity in the layer below. One possible interpretation of this is that the vertical motions associated with the gravity waves help localize the release of static instability that is generated through larger-scale processes occurring within the anvil outflow located above.

However, most reports of the observed light and moderate turbulence near the downstream anvil edge occurred within the $10.5-12.5 \mathrm{~km}$ MSL statically stable layer containing the strongest amplitude $\left(0.5-1.5 \mathrm{~m} \mathrm{~s}^{-1}\right)$ gravity wave vertical motions located beneath the layer of simulated static instability and TKE (cf. Figs. 1c,d and $15 \mathrm{~b})$. For these reports, the turbulence was situated within a deep layer of $\mathrm{Ri}<1$ (Fig. 10a) and could have been more directly associated with the gravity waves than was the simulated TKE.

Regardless of the precise roles of the anvil outflow and the trapped gravity waves on the turbulence observed in the current case, from the practical standpoint of avoidance it is important to recognize the clear relationship between the two. Specifically, strong convective outflow helped establish a wave duct that was critical to the maintenance and horizontal propagation of the trapped gravity waves. Such waves are easily identifiable in high-resolution visible satellite imagery (Fig. 1) and provide an important visual cue that turbulence is likely occurring at substantial distances (up to hundreds of kilometers) from the parent deep convection and may persist (up to a few hours) after this convection decays.

Vertical motions and turbulence within thunderstorm anvils are typically much weaker than in their parent deep convection. However, an important finding suggested by the current study is that the outer portions of such anvils, which are often thin and may appear relatively innocuous, can under certain conditions be particularly prone to turbulence. Clearly, additional case studies and climatological studies of trapped gravity waves in UTLS thunderstorm outflows are needed to better determine the relative risks of turbulence affecting commercial aviation that are associated with this phenomenon. Fortunately, high-resolution imagery from the GOES-R series of satellites (e.g., Schmit et al. 2017) should become increasingly available to identify additional cases for study since GOES-16 has become operational.

Acknowledgments. The authors benefited from discussions with George Bryan (NCAR/MMM), Teddie Keller (NCAR/RAL), and Kevin Haghi (University of Oklahoma). Improvements to the manuscript resulted from the constructive comments by the editor (Todd Lane) and two anonymous reviewers. This research is in response to requirements and funding by the U.S. Federal Aviation Administration (FAA). The views expressed are those of the authors and do not necessarily represent the official policy or position of the FAA. The National Center for Atmospheric Research is sponsored by the National Science Foundation.

\section{REFERENCES}

Barber, K. A., G. L. Mullendore, and M. J. Alexander, 2018: Outof-cloud convective turbulence: Estimation method and impacts of model resolution. J. Appl. Meteor. Climatol., 57, 121-136, https://doi.org/10.1175/JAMC-D-17-0174.1.

Bedka, K. M., J. Brunner, R. Dworak, W. Feltz, J. Otkin, and T. Greenwald, 2010: Objective satellite-based overshooting top detection using infrared window channel brightness 
temperature gradients. J. Appl. Meteor. Climatol., 49, 181-202, https://doi.org/10.1175/2009JAMC2286.1.

Bretherton, F. P., 1966: The propagation of groups of internal gravity waves in shear flow. Quart. J. Roy. Meteor. Soc., 92, 466-480, https://doi.org/10.1002/qj.49709239403.

Bryan, G. H., and J. M. Fritsch, 2000: Moist absolute instability: The sixth static stability state. Bull. Amer. Meteor. Soc., 81, 1207-1230, https://doi.org/10.1175/1520-0477(2000)081<1287: MAITSS $>2.3 . \mathrm{CO} ; 2$.

Bunkers, M. J., B. A. Klimowski, J. W. Zeitler, R. L. Thompson, and M. L. Weisman, 2000: Predicting supercell motion using a new hodograph technique. Wea. Forecasting, 15, 61-79, https:// doi.org/10.1175/1520-0434(2000)015<0061:PSMUAN>2.0.CO;2.

Clark, R., 2016: FP3 Ellis, KS radiosonde data, version 2.0. UCAR/ NCAR Earth Observing Laboratory, accessed 1 August 2017, https://doi.org/10.5065/D6GM85DZ.

Coniglio, M. C., D. J. Stensrud, and L. J. Wicker, 2006: Effects of upper-level shear on the structure and maintenance of strong quasi-linear mesoscale convective systems. J. Atmos. Sci., 63, 1231-1252, https://doi.org/10.1175/JAS3681.1.

Dörnbrack, A., T. Gerz, and U. Schumann, 1995: Turbulence breaking of overturning gravity waves below a critical level. Appl. Sci. Res., 54, 163-176, https://doi.org/10.1007/BF00849114.

Dudhia, J., 1989: Numerical study of convection observed during the Winter Monsoon Experiment using a mesoscale twodimensional model. J. Atmos. Sci., 46, 3077-3107, https://doi.org/ 10.1175/1520-0469(1989)046<3077:NSOCOD>2.0.CO;2.

Durran, D. R., and J. B. Klemp, 1982: On the effects of moisture on the Brunt-Väisälä frequency. J. Atmos. Sci., 39, 2152-2158, https://doi.org/10.1175/1520-0469(1982)039<2152: OTEOMO $>2.0 . \mathrm{CO} ; 2$

Ek, M. B., K. E. Mitchell, Y. Lin, E. Rogers, P. Grummann, V. Koren, G. Gayno, and J. D. Tarpley, 2003: Implementation of Noah land-surface model advances in the NCEP operational mesoscale Eta model. J. Geophys. Res., 108, 8851, https://doi.org/10.1029/2002JD003296.

Fovell, R. G., R. D. Sharman, and S. B. Trier, 2007: A case study of convectively-induced clear-air turbulence. 12th Conf. on Mesoscale Processes, Waterville Valley, NH, Amer. Meteor. Soc., P13.4, https://ams.confex.com/ams/pdfpapers/126190.pdf.

Geerts, B., and Coauthors, 2017: The 2015 Plains Elevated Convection At Night field project. Bull. Amer. Meteor. Soc., 98, 767-786, https://doi.org/10.1175/BAMS-D-15-00257.1.

Holdridge, D., and D. Turner, 2015: FP6 Hesston, KS radiosonde data, version 1.0. UCAR/NCAR Earth Observing Laboratory, accessed 1 August 2017, https://doi.org/10.5065/D6765CD0.

Homeyer, C. R., J. D. McAuliffe, and K. M. Bedka, 2017: On the development of above-anvil cirrus plumes in extratropica convection. J. Atmos. Sci., 74, 1617-1633, https://doi.org/ 10.1175/JAS-D-16-0269.1.

Janjić, Z. I., 2001: Nonsingular implementation of the Mellor-Yamada level 2.5 scheme in the NCEP Meso Model. NCEP Office Note 437, 61 pp., http://www.emc.ncep.noaa.gov/officenotes/ newernotes/on437.pdf.

Kim, J.-H., and H.-Y. Chun, 2012: A numerical simulation of convectively induced turbulence above deep convection. J. Appl. Meteor. Climatol., 51, 1180-1200, https://doi.org/ 10.1175/JAMC-D-11-0140.1.

Klemp, J. B., J. Dudhia, and A. D. Hassiotis, 2008: An upper gravitywave absorbing layer for NWP applications. Mon. Wea. Rev., 136, 3987-4004, https://doi.org/10.1175/2008MWR2596.1.

Koch, S. E., M. desJardins, and P. J. Kocin, 1983: An interactive Barnes objective map analysis scheme for use with satellite and conventional data. J. Climate Appl. Meteor., 22, 14871503, https://doi.org/10.1175/1520-0450(1983)022<1487: AIBOMA $>2.0 . \mathrm{CO} ; 2$.

Lane, T. P., and J. C. Knievel, 2005: Some effects of model resolution on simulated gravity waves generated by deep, mesoscale convection. J. Atmos. Sci., 62, 3408-3419, https://doi.org/ 10.1175/JAS3513.1.

, and R. D. Sharman, 2014: Intensity of thunderstorm-generated turbulence as revealed by large-eddy simulation. Geophys. Res. Lett., 41, 2221-2227, https://doi.org/10.1002/2014GL059299.

, - - T. L. Clark, and H.-M. Hsu, 2003: An investigation of turbulence generation mechanisms above deep convection. J. Atmos. Sci., 60, 1297-1321, https://doi.org/10.1175/15200469(2003)60<1297:AIOTGM>2.0.CO;2.

, - — S. B. Trier, R. G. Fovell, and J. K. Williams, 2012: Recent advances in the understanding of near-cloud turbulence. Bull. Amer. Meteor. Soc., 93, 499-515, https://doi.org/ 10.1175/BAMS-D-11-00062.1.

Levizzani, V., and M. Setvák, 1996: Multispectral, high-resolution satellite observations of plumes on top of convective storms. J. Atmos. Sci., 53, 361-369, https://doi.org/10.1175/15200469(1996)053<0361:MHRSOO>2.0.CO;2.

Miles, J., 1986: Richardson's criterion for the stability of stratified shear flow. Phys. Fluids, 29, 3470-3471, https://doi.org/ 10.1063/1.865812.

Mlawer, E. J., S. J. Taubman, P. D. Brown, M. J. Iacono, and S. A. Clough, 1997: Radiative transfer for inhomogeneous atmosphere: RRTM, a validated correlated- $k$ model for the longwave. J. Geophys. Res., 102, 16 663-16 682, https://doi.org/ 10.1029/97JD00237.

Muhlbauer, A., H. Kalesse, and P. Kollias, 2014: Vertical velocities and turbulence in midlatitude anvil cirrus: A comparison between in situ aircraft measurements and ground-based Doppler cloud radar retrievals. Geophys. Res. Lett., 41, 7814-7821, https://doi.org/10.1002/2014GL062279.

Nappo, C. J., 2002: An Introduction to Atmospheric Gravity Waves. Academic Press, $276 \mathrm{pp}$

Petre, J. M., and J. Verlinde, 2004: Cloud radar observations of KelvinHelmholtz instability in a Florida anvil. Mon. Wea. Rev., 132, 2520-2523, https://doi.org/10.1175/1520-0493(2004)132<2520: CROOKI $>2.0 . \mathrm{CO} ; 2$

Rotunno, R., and J. B. Klemp, 1982: The influence of the shear-induced pressure gradient on thunderstorm motion. Mon. Wea. Rev., 110, 136-151, https://doi.org/10.1175/1520-0493(1982)110<0136: TIOTSI $>2.0 . \mathrm{CO} ; 2$.

Schmit, T. J., P. Griffith, M. M. Gunshor, J. M. Daniels, S. J. Goodman, and W. J. Lebair, 2017: A closer look at the ABI on the GOES-R series. Bull. Amer. Meteor. Soc., 98, 681-698, https://doi.org/10.1175/BAMS-D-15-00230.1.

Schwartz, B., 1996: The quantitative use of PIREPs in developing aviation weather guidance products. Wea. Forecasting, 11, 372-384, https://doi.org/10.1175/1520-0434(1996)011<0372: TQUOPI $>2.0 . \mathrm{CO} ; 2$.

Sharman, R. D., and M. G. Wurtele, 1983: Ship waves and lee waves. J. Atmos. Sci., 40, 396-427, https://doi.org/10.1175/ 1520-0469(1983)040<0396:SWALW>2.0.CO;2.

, and S. B. Trier, 2018: Influences of gravity waves on convectively induced turbulence (CIT): A review. Pure Appl. Geophys., in press, https://doi.org/10.1007/s00024-018-1849-2. , J. D. Doyle, and M. A. Shapiro, 2012: An investigation of a commercial aircraft encounter with severe clear-air turbulence over western Greenland. J. Appl. Meteor. Climatol., 51, 42-53, https://doi.org/10.1175/JAMC-D-11-044.1. 
L. B. Cornman, G. Meymaris, J. Pearson, and T. Farrar, 2014: Description and derived climatologies of automated in situ eddy-dissipation-rate reports of atmospheric turbulence. J. Appl. Meteor. Climatol., 53, 1416-1432, https://doi.org/10.1175/ JAMC-D-13-0329.1.

Skamarock, W. C., and J. B. Klemp, 2008: A time-split nonhydrostatic atmospheric model for weather research and forecasting applications. J. Comput. Phys., 227, 3465-3485, https://doi.org/10.1016/j.jcp.2007.01.037.

Smith, T. L., S. G. Benjamin, J. M. Brown, S. S. Weygandt, T. Smirnova, and B. E. Schwartz, 2008: Convection forecasts from the hourly updated, 3-km High Resolution Rapid Refresh (HRRR) model. 24th Conf. on Severe Local Storms, Savannah, GA, Amer. Meteor. Soc., 11.1, http://ams.confex. com/ams/pdfpapers/142055.pdf.

Thompson, G., P. R. Field, R. M. Rasmussen, and W. D. Hall, 2008: Explicit forecasts of winter precipitation using an improved bulk microphysics scheme. Part II: Implementation of a new snow parameterization. Mon. Wea. Rev., 136, 5095-5115, https://doi.org/10.1175/2008MWR2387.1.

Trier, S. B., and R. D. Sharman, 2009: Convection-permitting simulations of the environment supporting widespread turbulence within the upper-level outflow of a mesoscale convective system. Mon. Wea. Rev., 137, 1972-1990, https://doi.org/10.1175/ 2008MWR2770.1.
R. G. Fovell, and R. G. Frehlich, 2010: Numerical simulation of radial cloud bands within the upper-level outflow of an observed mesoscale convective system. J. Atmos. Sci., 67, 2990-2999, https://doi.org/10.1175/2010JAS3531.1.

,-- , and T. P. Lane, 2012: Influences of moist convection on a cold-season outbreak of clear-air turbulence (CAT). Mon. Wea. Rev., 140, 2477-2496, https://doi.org/10.1175/MWR-D11-00353.1.

Vermeesch, K., 2015: FP2 Greensburg, KS radiosonde data, version 1.0. UCAR/NCAR Earth Observing Laboratory, accessed 1 August 2017, https://doi.org/10.5065/D6FQ9TPH.

Wang, P. K., 2003: Moisture plumes above thunderstorm anvils and their contributions to cross tropopause transport of water vapor in midlatitudes. J. Geophys. Res., 108, 4194, https://doi.org/ 10.1029/2002JD002581.

- 2007: The thermodynamic structure atop a penetrating convective thunderstorm. Atmos. Res., 83, 254-262, https://doi.org/ 10.1016/j.atmosres.2005.08.010.

—, S.-H. Su, M. Setvak, H. Lin, and R. M. Rabin, 2010: Ship wave signature at the cloud top of deep convective storms. Atmos. Res., 97, 294-302, https://doi.org/10.1016/ j.atmosres.2010.03.015.

Zovko-Rajak, D., and T. P. Lane, 2014: The generation of nearcloud turbulence in idealized simulations. J. Atmos. Sci., 71, 2430-2451, https://doi.org/10.1175/JAS-D-13-0346.1. 